\title{
Nanoparticles of alkylglyceryl dextran and poly(ethyl cyanoacrylate) for applications in drug delivery: preparation and characterisation
}

\author{
Daniel M. Ibegbu ${ }^{a, b}$, Asme Boussahel ${ }^{a}$,Simon Cragg ${ }^{c}$, John Tsibouklis $^{a}$, Eugen Barbu $^{a^{*}}$ \\ aschool of Pharmacy and Biomedical Sciences, University of Portsmouth, St Michael's Building, \\ White Swan Road, Portsmouth, PO1 2DT, United Kingdom \\ bepartment of Medical Biochemistry, University of Nigeria Enugu Campus (UNEC), Enugu, Nigeria

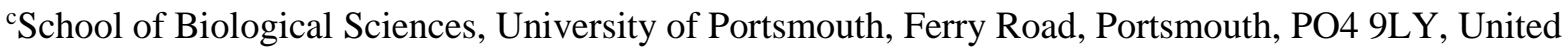 \\ Kingdom
}

*eugen.barbu@port.ac.uk; fax004492842511

\begin{abstract}
Toward the development of drug carriers that are capable of crossing biological membranes, controlled emulsion polymerisation has been utilised to produce nanoparticulate carriers from the combination of poly(alkyl cyanoacrylate) and alkylglyceryl dextran to a molecular structure designed to combine the non-immunogenic and stabilising properties of dextran with the demonstrated permeation enhancing ability of alkylglycerols. To this aim, a systematic series of alkylglyceryl dextrans have been synthesised and functionalised with ethyl or butyl cyanoacrylates to form stable polymeric nanocarriers $(100-500 \mathrm{~nm})$. Results of investigations into their capability to act as controlled-release devices and their cytotoxicity against bEnd3 cells are reported.
\end{abstract}

Keywords: nanoparticles; amphiphilic dextran; poly(ethyl cyanoacrylate); cytotoxicity. 


\section{Introduction}

One of the major inhibiting factors to the efficient treatment of brain disorders is the lack of universally applicable methods for transporting therapeutic agents across the blood-brain barrier (BBB) [1-4]. Therapeutic approaches to circumvent the BBB without altering its integrity represent an area of intense activity in drug research, and several methods have been proposed as potential means of improving the access of neuroactives to the brain [5]. Among these methods, the intravascular route is generally regarded as least invasive [4,6]. Variants of the approach include the: employment of biologically active agents (e.g. mannitol, histamine, nitric oxide, bradykinin, 5-hydroxytryptamine, or cytokines) [7,8]; chemical modification or formulation of drugs such that they mimic substrates of influx transporters [9]; and, the employment of nano-sized carriers [ 10,11], liposomes [12,13] and micro- or nano-sized drug transporters $[14,15]$.

Since colloidal carriers, particularly biodegradable polymeric nanoparticles, are often amenable to structural modifications that may bestow to them the capability to enhance drug permeation through the $\mathrm{BBB}$, many researchers regard these structures as promising vehicles for the delivery of drugs to the brain $[16,17]$.

Consequent to their proven biocompatibility (following extensive use as medical adhesives [18]), alkyl cyanoacrylates have long been identified as candidate materials for the fabrication of nanoparticulate vehicles for biomedical applications, especially for the transport of therapeutic agents across the BBB $[19,20]$. It has been shown that the coating of such nanoparticles with polysorbate 80 improves stability and enhances the prospect for the 
therapeutically useful delivery of actives to the brain $[19,21]$. While a note of caution has been sounded regarding the use of poly(butylcyanoacrylate) (PBCA; which has been shown by in vitro experiments to exhibit a time and concentration dependent toxicological effect $[22,23]$ that is linked to the products of its degradation [24]), the clinical-trial-data based toxicological evaluation of poly(isohexylcyanoacrylate) (PIHCA) did not unmask any adverse effects of therapeutic significance [25]. Although there are not any clinical trials data available for poly(ethylcyanoacrylate) (PECA), the ready availability of its precursor monomer, ECA, renders this polymer a candidate material for the fabrication of nanoparticulate vehicles for biomedical applications.

Since the stability of injectable nanoparticulate formulations can be improved by coating with surfactants, such as poly(ethylene glycol)s, or with non-toxic and non-immunogenic polysaccharides, such as dextran [26-29], and considering that alkylglycerols are known to encourage a transient increase in the transport of actives into the brain (when co-administered carotidally with antineoplastics or antibiotics [30-33]), alkylglyceryl-modified dextrans are among the materials investigated for their potential to enhance drug penetration across the BBB [34].

Rationalised by the assumption that a nanoparticulate drug-carrier system based on poly(ethyl cyanoacrylate) and dextran that had been modified with alkylglyceryl moieties may lead to improved particle stability and facilitate increased drug availability to the brain, we report on methods for the preparation of such a system and on the associated physicochemical characterisation and toxicity assessment against mouse brain capillary endothelial cells (bEnd3).

\section{Experimental}


General. Dextran from Leuconostoc (MW 6 and $100 \mathrm{KDa}$ ), anhydrous dimethyl sulfoxide (DMSO; $\geq 99.9 \%$ ), alkyl glycidyl ethers (butyl (G4); octyl (G8); dodecyl (G12); tetradecyl (G14); hexadecyl (G16)), potassium tert-butoxide (t-BuOK), ethyl 2-cyanoacrylate, $\mathrm{N}$ methylisatoic anhydride (MIA), anhydrous toluene (99.8\%), Sephadex ${ }^{\circledR}$ G-50, and esterase from porcine liver (lyophilized powder, $\geq 15$ units $/ \mathrm{mg}$ ) were obtained from Sigma-Aldrich, Gillingham, UK. Butyl cyanoacrylate was kindly donated by Henkel Ireland Ltd, Dublin. Doxorubicin hydrochloride was obtained from LGM Pharma, Nashville, USA; methanol and water (HPLC grade), tetramethylrhodamine-5-carbonyl azide (TMRCA), diethyl ether, acetone, dimethylformamide (DMF) and dichloromethane were obtained from Fisher Scientific, Loughborough, UK; high purity deionised water was sourced from a PURELAB Optima lab system ELGA High Wycombe, Bucks UK. Unless otherwise specified, all reagents were used as obtained. Dialysis was performed using Visking membrane (cut-off 12$14 \mathrm{kDa}$ or $3 \mathrm{kDa}$; Medicell International Ltd, London, UK), in deionised water. Cellulose nitrate $(0.2 \mu \mathrm{m})$ and polyether sulfonate membrane filters were obtained from Whatman, Maidstone, UK and Alpha Laboratories Ltd, Hampshire, UK respectively.

Solvents used for polymerisation were degassed using three freeze-thaw cycles. A Büchi Rotovapor R-200 equipped with a Sogevac Saskia PIZ 100 vacuum pump was used for solvent removal. Sonication was performed using a Grant ultrasonic bath XB3 (Farnell, UK). A Rotofix 32A Hettich (Zentrifugen-Germany), an Eppendorf MiniSpin (F-45-12-11 rotor; Eppendorf UK) and an X3 (50.2 Ti rotor; Beckman Coulter Ltd. UK) were used for centrifugation. Freeze drying was carried out by flash freezing in liquid nitrogen and using a Virtis ${ }^{\circledR}$ Benchtop instrument, SP Industries-Warminster, USA. An orbital shaking water bath with thermostat (Grant OLS 200, Farnell, UK) was used for drug-release studies and for the enzyme-induced degradation study. 
Materials were characterised by ${ }^{1} \mathrm{H}-\mathrm{NMR}$ (400 MHz) spectroscopy using a JEOL Eclipse 400+ instrument (Jeol, UK), in DMSO- $\mathrm{d}_{6}$ with $0.2 \%$ TMS; spectra were processed using JEOL Delta v 5.0.2 software. FT-IR spectra were recorded using a Nicolet 6700 instrument (Thermo Scientific, UK) equipped with an ATR Smart Orbit accessory with diamond crystal (128 scans; $\left.4 \mathrm{~cm}^{-1}\right)$ and controlled by Omnic Specta 8.0 software. MALDI-TOF MS experiments were performed on a Micromass MALDI MicroMX instrument operating in positive reflectron mode ( $\mathrm{m} / \mathrm{z}$ range $400-1600 ; 337 \mathrm{~nm}$ laser) with $\alpha$-cyano-4hydroxycinnamic acid (CHCA) matrix. The molecular weight of alkylglyceryl dextrans was determined using a Waters Alliance GPC 2000 instrument (PL-aquagel-OH column; 0.6 $\mathrm{mL} / \mathrm{min}$ 80:20 water/methanol; $30{ }^{\circ} \mathrm{C}$; refractive index detector). The calibration was performed using Pullulan standards (Shodex Denko) in the MW range $0.6 \times 10^{4}-80.5 \times 10^{4}$. TG and DSC analyses $\left(10 \mathrm{~K} / \mathrm{min}\right.$ heating rate; $\left.\mathrm{N}_{2}\right)$ were performed on TG $209 \mathrm{~F} 1 \mathrm{Libra}$ and DSC 214 ASC Polyma instruments (Netzsch, Germany).

Statistical analysis was performed using SPSS version 22 software; significance was tested using one-way analysis of variance (ANOVA) followed by Scheffe posthoc test ( $\mathrm{p}$ values were set at level 0.05 , unless stated otherwise). Data are presented as mean \pm standard deviation.

Synthesis of alkylglyceryl modified-dextrans (Dex6G4; Dex6G8; Dex6G12; Dex6G14; Dex6G16; Dex100G4; Dex100G8; Dex100G12; Dex100G14; Dex100G16). To a solution of dextran (2 g; MW either $6 \mathrm{kDa}$ or $100 \mathrm{kDa} ; 12.35 \mathrm{mmol}$ glucose equivalent) in anhydrous DMSO $(150 \mathrm{~mL})$ stirred at $40{ }^{\circ} \mathrm{C}$ under nitrogen, a solution of potassium tert-butoxide $(\mathrm{t}$ BuOK; $1.385 \mathrm{~g}, 12.35 \mathrm{mmol})$ in anhydrous DMSO (50 mL) was gradually added. Stirring was continued for $2 \mathrm{~h}$ before the drop wise addition of a solution of alkyl glycidyl ether (either butyl (G4; $7.03 \mathrm{ml} ; 48.9 \mathrm{mmol})$, octyl (G8; $10.17 \mathrm{ml} ; 49.17 \mathrm{mmol})$, lauryl (G12; 2.99 
$\mathrm{g} ; 12.35 \mathrm{mmol})$, tetradecyl (G14; $4.16 \mathrm{ml} ; 12.39 \mathrm{mmol})$, or hexadecyl (G16; $3.68 \mathrm{~g} ; 12.35$ mmol)). After stirring for a further $24 \mathrm{~h}$, the reaction mixture was transferred into a dialyzingmembrane bag (MWCO 3.5 for modified $6 \mathrm{kDa}$ dextrans, and MWCO 12-14 kDa for modified $100 \mathrm{kDa}$ dextrans) and dialysed against deionised water for five days. The content of each dialysis bag $(c a .400 \mathrm{~mL})$ was then washed with diethyl ether $(3 \times 150 \mathrm{~mL})$ in a separating funnel, traces of volatile solvents were removed from the aqueous layer under reduced pressure using a rotary evaporator, and the material was again dialyzed ( $48 \mathrm{~h}$ ) to remove any remaining traces of water-soluble impurities. Lyophilisation afforded the corresponding alkylglyceryl-modified dextrans as white powders (40-60 \% yield), which were characterized by ${ }^{1} \mathrm{H}$ - and ${ }^{13} \mathrm{C}-\mathrm{NMR}$, MALDI-TOF MS, TGA and DSC. ${ }^{1} \mathrm{H}$-NMR (400 $\left.M H z ; D M S O-d_{6} ; \delta p p m\right): 0.86\left(\mathrm{t}, \mathrm{CH}_{3}\right) ; 1.3$ and 1.5 (m, alkyl groups); 3.5-3.9 (m, pyranose); 4.5-5.1 (m, anomeric H at C1). ${ }^{13} \mathrm{C} N M R\left(101 \mathrm{MHz}, \mathrm{DMSO}-d_{6}\right) \delta p p m$ 14.50-31.85 (alkyl glyceryl carbons), Dextran-66.69 (C-6), 70.71 (C-2), 72.42 (C-5), 73.90 (C-3), 98.80 (anomeric-C-1). FTIR (ATR; $\left.v_{\max } ; \mathrm{cm}^{-1}\right): 3,398$ (O-H str, OH glycerol); 2,925; 2,862 (C-H str, pyranose ring, $\mathrm{CH}_{2}$ of alkyl group); 1,379 (C-H def, $\left.\mathrm{CH}_{3} \mathrm{CO}\right) ; 1,150 ; 1,072 ; 1,028$ (C-O-C str, glycoside linkage).

Preparation of alkylglyceryl dextran-poly(ethyl 2-cyanoacrylate) nanoparticles by controlled emulsion polymerisation. Ethyl 2-cyanoacrylate (ECA) $(600 \mu \mathrm{L})$ was added dropwise to alkylglyceryl-dextran $(100 \mathrm{mg})$ in deionised water $(100 \mathrm{~mL} ; \mathrm{pH} 2.5, \mathrm{HCl})$ and the mixture was stirred at room temperature for $4 \mathrm{~h}$. After this time the solution was neutralised with $\mathrm{NaOH}$ solution $(1 \mathrm{~N})$, centrifuged for $15 \mathrm{~min}(3000 \mathrm{rpm}$; $1502 \mathrm{~g}$; Rotofix) and further ultracentrifuged for $30 \mathrm{~min}(12,200 \mathrm{rpm} ; 18000 \mathrm{~g}$; Beckman ultracentrifuge). The pellet was rinsed with deionized water $(10 \mathrm{~mL} ; 3 \times)$, then dispersed again in water $(10 \mathrm{~mL} ; 10 \mathrm{~min}$ sonication) followed by freeze drying. 
Preparation of alkylglyceryl dextran-poly(ethyl 2-cyanoacrylate) nanoparticles by emulsion polymerisation in a water-acetone mix. A solution of ECA $(150 \mu \mathrm{l})$ in acetone $(50 \mathrm{~mL})$ was added gradually under stirring to alkyl glyceryl dextran $(250 \mathrm{mg})$ in deionised water $(50 \mathrm{~mL})$. Stirring was continued overnight at room temperature, after which time the mixture was centrifuged (40,000 rpm, 193,011 g; $30 \mathrm{~min})$, the resulting nanoparticles were rinsed with water (followed by centrifugation) and re-suspended in deionised water (10 $\mathrm{mL})$ prior to freeze drying.

Nanoparticles characterisation. The resulting nanoparticulate white powders were characterised by ${ }^{1} \mathrm{H}$ - NMR spectroscopy as well as elemental and thermogravimetric analysis. Dispersions of these nanoparticles (concentration range $10-100 \mu \mathrm{g} / \mathrm{mL}$ ) were prepared by vortex and sonication in deionized water or PBS.

A Malvern Zetasizer Nano ZS instrument equipped with a $633 \mathrm{~nm} \mathrm{He}-\mathrm{Ne}$ laser $\left(173^{\circ}\right.$ backscattering angle detection) and controlled by Zetasizer v7.01 software was used to determine the hydrodynamic diameter of nanoparticles; samples were analysed in triplicate using disposable polycarbonate cuvettes (equilibration time $2 \mathrm{~min}$ at $25^{\circ} \mathrm{C}$ ). Results of cumulative analyses were expressed as Z-average values (Z-av) and the associated polydispersity index (PDI). Zeta potential was determined from electrophoretic mobility measurements (EPM) using the same instrument; samples were measured in folded capillary cells (DTS1070, Malvern) and data was processed according to Smoluchowski's model (Henry's function $\mathrm{f}(\mathrm{ka})=1.5$ ). An MTP-2 (Multi-Purpose Titrator-2, Malvern, UK) equipped with a solvent degasser was employed for the investigation of $\mathrm{pH}$-dependent behaviour: samples $(10 \mathrm{~mL}$ each) were titrated automatically against aq. $\mathrm{HCl}$ solutions $(5 \mathrm{mM}$ or $50 \mathrm{mM})$ from $\mathrm{pH} 8$ to $\mathrm{pH} 3$; all samples were filtered (Whatman $0.2 \mu \mathrm{m}$ PES filters) prior to use. The morphology of nanoparticles was investigated by Scanning Electron Microscopy (SEM); powdered samples were deposited onto mica that had been adhered onto aluminium stubs and 
secured under a flow of nitrogen. Samples were sputter-coated with Au/Pd under Ar using a Quorum Q150RES coater (Quorum Technologies Ltd., UK) and imaged using a JEOL-JSM6060LV SEM Microscope. Transmission electron microscopy (TEM) studies were performed using a TEM/JEOL-2000FX instrument (JEOL Ltd, Japan); samples were deposited as an aqueous dispersion on $3.05 \mathrm{~mm}$ copper grids with formvar/carbon support film (300 mesh), followed by drying.

\section{Model drug loading and release studies.}

Doxorubicin hydrochloride was loaded into nanoparticles during their preparation: a solution of ECA $(150 \mu \mathrm{L})$ in acetone $(25 \mathrm{~mL})$ was added gradually to a stirring mixture of modified dextran (either Dex6G4 or Dex6G8; $25 \mathrm{mg}$ ) in deionized water $(25 \mathrm{~mL})$ followed by the addition of a solution of Doxorubicin hydrochloride $(2 \mathrm{mg})$ in acetone $(1 \mathrm{~mL})$. The mixture was allowed to stir overnight at room temperature, and the resulting colloidal suspension was separated by centrifugation $(40,000 \mathrm{rpm} ; 145421 \mathrm{~g} ; 30 \mathrm{~min})$; the amount of unloaded Doxorubicin hydrochloride left in the supernatant was determined using a Varian Cary Fluorescence spectrophotometer (480 nm / $590 \mathrm{~nm}$ excitation / emission wavelengths).

For release studies, the centrifuged pellet was dispersed in deionised water $(10 \mathrm{~mL})$ by sonication (10 $\mathrm{min})$ and an aliquot $(5 \mathrm{~mL})$ of each sample (either PECA-Dex6G4-Dox or PECA-Dex6G8-Dox) was placed in a dialysis membrane bag that had been immersed in Falcon tubes containing PBS $(20 \mathrm{~mL})$. The tubes were incubated in an oscillating water bath $\left(37^{\circ} \mathrm{C} ; 100 \mathrm{rpm}\right)$ and, at specified time intervals, an aliquot $(1 \mathrm{~mL})$ was withdrawn and replaced with fresh media. Fluorescence intensity was measured in the supernatant and the amount of drug released at each time point was quantified by means of a calibration curve. The calculated amount of the equivalent content of free Doxorubicin hydrochloride in nanoparticles was used as control. 
Curcumin was loaded by stirring (overnight, room temperature) PECA-Dex100G4 nanoparticles in an ethanol-water $(1: 1 \mathrm{v} / \mathrm{v})$ solution of curcumin $(0.1 \mathrm{mg}$ in $1 \mathrm{~mL})$. The sample was centrifuged (mini-spin Eppendorf, 12200 rpm, 9984 g; 15 min) and absorbance of an aliquot taken from the supernatant $(1 \mathrm{~mL})$ to which $2 \mathrm{~mL}$ of DMSO had been added was measured to determine the degree of loading with reference to a standard calibration plot of curcumin in ethanol-water $(1: 1 \mathrm{v}: \mathrm{v})$.

Evaluation of Evans blue retentive capacity of PECA-alkyl glyceryl dextran nanoparticles. ECA $(150 \mu \mathrm{g})$ in acetone $(25 \mathrm{~mL})$ was added to a stirring solution of Dex6G4 $(25 \mathrm{mg})$ dispersed in deionized water $(25 \mathrm{~mL})$ containing Evans Blue $(6 \mathrm{mg})$. Stirring was continued overnight at room temperature then the mixture was pre-spun (1500 rpm; $322 \mathrm{~g} ; 5 \mathrm{~min})$ and ultracentrifuged (12200 rpm; 18000g; $30 \mathrm{~min}$ ). The Evans blue-loaded nanoparticles were dispersed in deionised water $(10 \mathrm{ml})$ and loading capacity was determined by reference to a calibration curve.

To evaluate the retentive capacity of nanoparticles, the colloidal mixture formed after loading Evans Blue to PECA-Dex6G4 nanoparticles was centrifuged twice and, after each centrifugation cycle, the absorbance of the supernatant was measured. The degree of loading after the second centrifugation was determined as $0.016 \%$ and the efficiency of entrapment was $2.034 \%$. Similar results were obtained for the entrapment of Evans blue into PECADex6G12 nanoparticles. Generally, nanoparticles loaded with Evans blue via the monomer polymerisation method exhibited poor entrapment efficiency and a correspondingly low degree of loading; since Evans blue is a negatively charged dye, it is likely that the negative zeta potential of PECA-alkyl glyceryl dextran nanoparticles is accountable for the poor compatibility displayed by this dye-nanoparticle system.

\section{Fluorescent labelling}


The fluorescent tagging of nanoparticles with MIA was performed by adapting a previously reported method [35], as follows: to a dispersion of PECA-Dex100G8 nanoparticles (20 mg) in ethanolic sodium borate buffer $(10 \mathrm{~mL})$, a solution of MIA $(20 \mathrm{mg})$ in ethanol $(0.2 \mathrm{~mL})$ was added under sonication/vortexing (10 $\mathrm{min})$; the mixture was dialysed $(72 \mathrm{~h})$ and freeze dried before the isolation of fluorophore-rich fractions by column chromatography. To this end, the column (Sephadex 50) was eluted with deionised water; the MIA-labelled nanoparticles were detected with a UV lamp (350 / $445 \mathrm{~nm}$ as MIA excitation / emission wavelengths).

Labelling of tetramethyl rhodamine-5-carbonyl azide (TMRCA) to PECA-Dex6G12 nanoparticles

A mixture of PECA-Dex6G12 nanoparticles $(50 \mathrm{mg})$ dispersed in anhydrous toluene $(20 \mathrm{~mL})$ and TMRCA $(0.6 \mathrm{mg})$ was stirred at $80{ }^{\circ} \mathrm{C}$ for $5 \mathrm{~h}$ under nitrogen, according to a similar literature protocol [36]; the mixture was dialysed (3500 MWCO) against DMF (72 h) and then deionised water (4 day) before freeze drying.

Biodegradation studies. ECA (2.5 g) was added drop wise, over $3 \mathrm{~h}$ under stirring, to a solution of Dex100G4 (250 mg; $0.1 \%$ w/v) in deionized water (pH 3, adjusted with $\mathrm{HCl}$; $25^{\circ} \mathrm{C}$ ). After this time, specified volumes (Table S1, Supplementary material) of a solution of porcine liver esterase $(2 \mathrm{mg} / \mathrm{mL})$ in phosphate buffer $(\mathrm{pH} 7)$ were each added to nanoparticle suspensions $(3.5 \mathrm{~mL})$ that had been mixed with $30 \mathrm{~mL}$ of Ringer's solution. The resulting mixtures and control (nanoparticle suspension mixed with Ringer's solution) were incubated in a shaking water bath $\left(37^{\circ} \mathrm{C}\right)$. The withdrawal of aliquots at time points up to 84 $\mathrm{h}$ allowed the monitoring of variation in nanoparticle size and PDI (as measured by DLS; Malvern Zetasizer Nano ZS). 
Cell culture. Dulbecco's Modified Eagle Medium (DMEM) media, TrypLE Express ${ }^{\mathrm{TM}}$, Phosphate Buffered Saline (PBS), MTT Cell Proliferation Assay Kit and Triton X-100 were sourced from Invitrogen Life Technologies, Paisley, UK. Recovery ${ }^{\mathrm{TM}}$ Cell Culture Freezing Medium and distilled water (cell culture quality) were obtained from Gibco, Paisley, UK. Trypan blue and L-cysteine were purchased from Sigma Aldrich, Gillingham, UK. Cryo-vials Greiner bio-one and sterile Nunc 96 well-plates were obtained from Fisher Scientific, Loughborough, UK. Nunclon F 96-well plates were sourced from Thermo Scientific, UK.

Immortalised mouse brain endothelial cells (bEnd3) were obtained from the Health Protection Agency Culture Collections UK and were cultured under a humidified atmosphere $\left(5 \% \mathrm{CO}_{2}\right)$ in a Nuaire DH AUTOFLOW air-jacketed incubator at $37^{\circ} \mathrm{C}$ and in small $\mathrm{T} 25$ culturing flasks (media is presented as Supplementary material). Cells were counted using a disposable haemocytometer, and the analysis of well-plates was performed using a POLAR star Optima (BMG Labtech) plate reader.

Cytotoxicity assay. An MTT assay was used to assess the cytotoxicity of nanoparticles (formulated from PECA-Dex100G4 and PBCA-Dex100G4) against bEnd3 cells. Nanoparticles dispersed in modified DMEM (10-100 $\mu \mathrm{g} / \mathrm{mL}$; sonication) were incubated with confluent bEnd3 cells (seeding $1 \times 10^{4}$ cells) for $24 \mathrm{~h}$. Sterile PBS and Triton X-100 (0.1\% w/v in PBS) provided the negative and positive controls, respectively.

\section{Results and discussion}

Dextrans of different molecular weight (6 and $100 \mathrm{kDa}$ ) were grafted with alkylglyceryl chains (butyl, octyl, dodecyl, tetradecyl, or hexadecyl) via nucleophilic substitution using alkyloxy-substituted oxiranes in the presence of potassium t-butoxide. The resulting modified dextrans: butylglyceryldextrans (Dex100G4, Dex6G4); octylglyceryl dextrans (Dex100G8, 
Dex6G8); dodecylglyceryl dextrans (Dex100G12, Dex6G12); tetradecylglyceryl dextrans (Dex6G14, Dex100G14); and hexadecylglyceryl dextrans (Dex100G16, Dex6G16 - where 6 or 100 denote the molecular weight of the original dextran, and 4, 8, 12, 14 or 16 denote the length of the alkyl substituent) were characterized by ${ }^{1} \mathrm{H}$ and ${ }^{13} \mathrm{C}-\mathrm{NMR}$, TGA, DSC, MALDITOF MS. These materials were further used for the preparation of nanoparticles in a method involving the in situ emulsion polymerisation of ethyl and/or butyl cyanoacrylates.

The successful functionalisation of dextran with alkyl glyceryl chains was evidenced by FTIR and ${ }^{1} \mathrm{H}-/{ }^{13} \mathrm{C}-\mathrm{NMR}$ spectroscopies as new bands indicative of secondary alcohol and ether groups: $1127 \mathrm{~cm}^{-1}(\mathrm{C}-\mathrm{O}-\mathrm{C}) ; 1343 \mathrm{~cm}^{-1}(\mathrm{O}-\mathrm{C}-\mathrm{H}) ; 1539 \mathrm{~cm}^{-1}\left(\mathrm{CH}_{2}\right)$; and, $0.86 \mathrm{ppm}(3 \mathrm{H}$, $\left.\mathrm{CH}_{3}\right), 1.3 \mathrm{ppm}\left(2 \mathrm{H}, \mathrm{CH}_{2}\right)$ and $1.5 \mathrm{ppm}\left(2 \mathrm{H}, \mathrm{CH}_{2}\right)$. Observed chemical shifts over the ranges 65 ppm - 99 ppm and 3 ppm - 5.2 ppm, respectively for ${ }^{13} \mathrm{C}$ - and ${ }^{1} \mathrm{H}-\mathrm{NMR}$, were consistent with those that are characteristic of dextran [37-40]; the signal of the anomeric proton ( $\mathrm{C} 1$, $4.67 \mathrm{ppm})$ was well separated from other resonances of the glucopyranosyl ring (3.2$3.7 \mathrm{ppm}$ ); the hydroxyl groups of dextran were manifested as a multiplet at $4.96 \mathrm{ppm}$.

The degree of substitution (DS\%, expressed as the number of alkylglyceryl chains per 100 glucopyranose units of dextran) was calculated from the ${ }^{1} \mathrm{H}-\mathrm{NMR}$ spectra using Equation 1:

$$
D S[\%]=\frac{\frac{1}{3} \times \int C 4 \prime}{\int C 1} \times 100
$$

where $\mathrm{C}^{\prime}$ ' is the integral of the signal assigned to the alkyl chain $\mathrm{CH}_{3}$ end group (0.86 ppm), and $\mathrm{C} 1$ is the integral of the signal assigned to the anomeric proton $(4.67 \mathrm{ppm})$.

The degree of substitution, which varied widely (from 50 to $150 \%$, Table 1), was found to increase with reaction time and with the excess of oxirane employed. Since the reactivity of the $\mathrm{OH}$ group of dextran towards alkylating agents is known to decrease in the order $\mathrm{C} 2>\mathrm{C} 4$ 
$>$ C3 [41] (likely due to the proximity to the anomeric C1 carbon [42]), it can be reasonably assumed that primary hydroxy groups were reacted with alkylglyceryl chains preferentially. No notable chain-length or molecular-weight dependent variations in the degree of substitution of the commercial dextrans employed were observed in this study.

The FTIR spectra of native dextran is characterised by skeletal vibrational modes $(\delta \mathrm{C}-\mathrm{C}-\mathrm{C}$, $\delta \mathrm{C}-\mathrm{C}-\mathrm{O}, \delta \mathrm{C}-\mathrm{O}$ and $\left.\tau \mathrm{C}-\mathrm{C} ; 400-700 \mathrm{~cm}^{-1}\right)$, the relative intensity of which is a function of water content. The grafting of alkyl glycerol chains on dextran was witnessed by FTIR as new secondary alcohol groups: the band at $1012 \mathrm{~cm}^{-1}$ is assigned to the vibrational mode of $\mathrm{C}-\mathrm{O}$; crystalline dextran is characterised by two absorptions at 851 and $914 \mathrm{~cm}^{-1}$, which are respectively assigned to the $\mathrm{C}-\mathrm{C}$ and $\mathrm{C}-\mathrm{H}$ bending modes. The absorption bands in the spectral range $1200-1500 \mathrm{~cm}^{-1}$ are primarily associated with $\mathrm{CH}$ deformation and $\mathrm{C}-\mathrm{O}-\mathrm{H}$ bending vibrations [43]. Bands at $2921 \mathrm{~cm}^{-1}$ and at $3215 \mathrm{~cm}^{-1}$ are respectively consistent with $\mathrm{C}-\mathrm{H}$ and $\mathrm{O}-\mathrm{H}$ stretching vibrations [43]. The alkyl groups were further evidenced by the symmetric and antisymmetric vibrations of aliphatic $\mathrm{CH}_{2}$ moieties at $c a .2920$ and $2860 \mathrm{~cm}^{-1}$.

\section{Figure 1.}

Pullulan standards allowed the determination by GPC of the molecular weight distribution profile of the synthesised alkylglyceryl dextrans and that of the starting material. Owing to differences in the experimental protocol, the average molecular weights of commercial dextrans that served as starting materials (Dex $6 \mathrm{kDa}$ and Dex $100 \mathrm{kDa}$ ) were higher than those claimed by the manufacturer. In accord with expectation, a study involving Dex100 showed that the synthesised Dex100G16 (DS 144.92\%) had a higher average molecular weight (188.309 kDa) than its precursor macromolecule Dex100 (109.399 kDa). Indicative of the comparative nature of the technique, GPC-determined values did not match those 
calculated from NMR data (366.62 kDa for Dex100G16). Similarly, the GPC-determined average molecular weight of Dex6G4 (DS $87.7 \%)$ was lower $(5.469 \mathrm{kDa})$ than that calculated from NMR data $(10.228 \mathrm{kDa})$ and, interestingly, lower than that measured by GPC for its precursor dextran (Dex6; $9.811 \mathrm{kDa})$. Irrespective of molecular weight, the PDI values of synthesised alkyl glyceryl dextrans (e.g. 1.0 for Dex100G16 and 1.5 for Dex6G4) were lower than those of precursor dextrans (e.g. 4.4 for Dex100 and 2.3 for Dex6), which is consistent with the assumption that the purification process that follows the grafting of alkylglyceryl chains to dextrans reduces the polydispersity of materials.

\section{Table 1 .}

Thermogravimetric analysis of alkylglyceryl dextrans revealed two discrete mass loss events (Figure 2A,B and Table 1): the first event represents loss of water and the second, which occurs over the temperature range $200-350{ }^{\circ} \mathrm{C}$, is due to the thermal degradation of either dextran or alkylglyceryl dextran structures $[44,45]$. To investigate the variation in hydrophilicity across the range of synthesised materials, the percentage of water mass loss was represented as a function of the alkyl chain length (Figure 2C); for Dex6- and Dex100based materials, the water content was found to decrease with increasing alkyl-chain length (the longer the alkyl chain length, the less hydrophilic the sample and the lower its water content). This was however not reflected in the behaviour of Dex6G8, Figure 2C, due to its higher degree of functionalization (115\%, compared to $65 \%$ for Dex100G8; Table 1). Irrespective of molecular weight, the residual mass of alkyl glyceryl dextrans was found to be lower than that of the corresponding unmodified dextrans, and did not appear to correlate with the alkyl chain length (Table 1).

Figure 2.

Table 2. 
DSC data did not provide any evidence for the presence of crystallinity in any of the samples under study. Interestingly, two glass transition events were identified in samples of the unmodified dextran (Figure 2D) and also in those of short-chained alkylglyceryl dextrans. Dextrans substituted with long alkyl chains (octyl or longer) did not exhibit the higher temperature glass transition (Table 2). In accord with TG data, the total enthalpy change characterising the evaporation of residual water (seen as a large endotherm in the first DSC run, e.g. Figure 2D; summarized in Table 2) decreases with increasing alkyl chain length. The temperature values for the first glass transition (expressed as median points) were slightly higher for materials based on the high molecular weight dextrans (Dex 100) than for those based on Dex6.

In situ anionic emulsion polymerisation of ethyl cyanoacrylate in the presence of alkylglyceryl dextrans resulted in the formation of alkylglyceryl-dextran-poly(ethyl cyanoacrylate) nanoparticles. To effect control over the rate of polymerization, reactions were carried out under acidic conditions ( $\mathrm{pH} 2.5)[19,22,46]$. Following purification and drying, nanoparticles were isolated as white powders that were characterized by NMR and elemental analysis. Nanoparticles were also formulated without $\mathrm{HCl}$, in a water-acetone mix (Table 3, samples 6 and 10), but this appears to be of little influence on the elemental composition (i.e. on the ratio of PECA to alkylglyceryl dextran found in the nanoparticles). Figure 3.

NMR spectra of PECA-alkylglyceryl dextran nanoparticles (typical example in Figure 3, PECA-Dex100G8) showed well-defined resonances that are characteristic of PECA (1.3 ppm; $4.2 \mathrm{ppm})$ and alkylglyceryl dextran (0.86 ppm, t, $\mathrm{CH}_{3} ; 1.3-1.5 \mathrm{ppm}, \mathrm{m}, \mathrm{CH}_{2} ; 3.5-3.9$ and 4.5-5.1 ppm, pyranose). Indicative of a high ratio of PECA to alkylglyceryl dextran moieties in nanoparticles, the NMR spectral features of alkylglyceryl dextran were of lower 
intensity than those due to the PECA component. This was supported by the elemental analysis results, which allowed the quantification of the constitutional units of nanoparticles (Table 3); the ratio of PECA to alkylglyceryl dextran in the nanoparticles was calculated from the percentage composition of carbon, nitrogen, oxygen, and hydrogen, and compared with theoretically calculated values. Across the range of the synthesized materials, alkylglyceryldextran accounted for a variable percentage (about 4 to $20 \%$ ) of the structural component of nanoparticles (Table 3). Consistent with findings regarding the ratio of dextran to alkyl cyanoacrylate, the elemental-analysis-determined percentage composition (w/w) of dextran and poly (isobutyl cyanoacrylate), PIBCA, is reported at $22 \%$ and $78 \%$, respectively [26]. Since sequential washing and centrifugation of nanoparticles from dextran and BCA is known to gradually increase the PBCA:dextran ratio (up to $c a .9: 1$ ), it may be reasonably assumed that a proportion of the dextran component is associated with the nanoparticles via physisorption [47].

Table 3.

Mass spectroscopy investigations by MALDI-TOF revealed a spectral pattern with characteristic peak-to-peak mass differences of 130.2 and 146.2, likely due to fragmentation at the $\mathrm{O}-\mathrm{C}$ bond level (Figure 4A). This is indicative of a fragmentation pathway that is characterised by the loss of $\mathrm{C}_{7} \mathrm{H}_{14} \mathrm{O}_{2}$ and $\mathrm{C}_{7} \mathrm{H}_{14} \mathrm{O}_{3}$ fragments (MW 130.18 and $146.18 \mathrm{Da}$, respectively), which in turn confirms the successful chemical grafting of native dextran with butylglyceryl pendent chains; no cross-ring fragments could be identified (Figure 4A). A similar pattern was observed for nanoparticles, as exemplified by those of PECA-Dex6G4 in Figure 4B. The failure to detect molecular ions is attributed to the $\alpha$-cyano-4hydroxycinnamic acid (CHCA) matrix used (a strong acid in the gaseous phase), which tends to induce extensive fragmentation [48,49]; it has been suggested that 2,5-dihydroxybenzoic acid (2,5-DHB) might be a better matrix than CHCA for the MALDI-TOF MS study of high 
molecular weight polysaccharides (such as dextran) that require a high matrix-to-analyte ratio to give enhanced signals $[49,50]$.

Figure 4.

Figure 5.

The size of PECA-Dex100G4 nanoparticles prepared by emulsion polymerisation ranged from 100 to $500 \mathrm{~nm}$. Indicative of the good aqueous stability characterising these nanoparticles, and in marked contrast with the zeta potential reported in the literature for PBCA nanoparticles $(-5.3 \pm 0.7 \mathrm{mV}$ [20]), zeta potentials were found to be lower than -30 $\mathrm{mV}$.

Investigations of the morphology of freeze-dried PECA-Dex100G4 nanoparticles prepared by emulsion polymerisation indicated a spherical shape (Figure 5); aggregates observed in SEM had been formed during the evaporation of liquid media at the sample preparation stage. The size differences observed when comparing these images with those obtained for the same type of nanoparticles by DLS, when measured in colloidal form, are likely due to the hydration of the outer layer and possibly due to an induced conformational change of the polymer chains at the surface of nanoparticles [51].

Figure 6.

To evaluate the stability of PECA and PECA-alkylglyceryl nanoparticles as a function of $\mathrm{pH}$, the size and zeta potential of nanoparticles re-dispersed in ultrapure water (example in Figure 6) were monitored during automatic $\mathrm{pH}$ titrations with aq. $\mathrm{HCl}(0.005 / 0.05 \mathrm{M})$. Results showed that, for all formulations, the average particle sizes at $\mathrm{pH} 7.4$ were in the range 100$500 \mathrm{~nm}$ and the zeta potential between -15 and $-30 \mathrm{mV}$. It was found that the zeta potential of PECA nanoparticles and PECA-alkylglyceryl dextran nanoparticles increased with decreasing $\mathrm{pH}$, with isoelectric points at low $\mathrm{pH}$ values $(<3.2)$. Although $\mathrm{pH}$-induced 
changes in the size of nanoparticles were observable, the average nanoparticle size was relatively stable over the $\mathrm{pH}$ range 3-8; PECA-Dex6G16 nanoparticles were least amenable to $\mathrm{pH}$-induced variations in size (Figure 6).

To investigate the esterase-induced biodegradation of nanoparticles, experiments using PECA-Dex100G4 nanoparticles and different enzyme concentrations were carried out according to standard literature procedures [52]. Data obtained in an $84 \mathrm{~h}$ degradation study indicate that, in agreement with a study involving PBCA nanoparticles [52], all sample sets treated with low enzyme concentrations exhibited a decrease in average size during the first few hours of the experiment (Figure 7a). However, at $4 \mathrm{~h}$ from the onset of the experiment, samples treated with high enzyme concentrations ( $\geq 420$ units) exhibited increased sizes relative to those measured at the $1 \mathrm{~h}$ time point; this increase appears to be directly related to enzyme concentration and to signal the initiation of aggregation. The degradation pattern observed with samples treated with low concentrations of enzyme (up to 220 units) could be consequent to surface degradation (PECA-nanoparticles are known to be susceptible to surface degradation [53]) whereby PECA-Dex100G4 nanoparticles become depleted over time; the time-dependent increase in size observed for samples treated with higher enzyme concentration may be explained in terms of agglomeration that is consequent to the significant degradation of the nanoparticulate structure; considering the high concentration of esterase, it is possible that depleted nanoparticles play a significant role in this process. In agreement with published data [54], the study shows that the degradation of nanoparticles is dependent on both time and enzyme concentration. Indicative of the strong degradative action of the enzyme, PDI increased over time but at a decreasing rate towards the end of the experiment, especially for samples that had been treated with high concentrations of the enzyme (Figure 7b).

\section{Figure 7.}


The drug loading capacity of PECA-alkylglyceryl dextran nanoparticles loaded with Doxorubicin hydrochloride and their drug release profiles appear to be affected by the alkyl chain length of the modified dextran (Figure 8). PECA-Dex6G4 nanoparticles accommodated a smaller load of Doxorubicin hydrochloride than PECA-Dex6G8 nanoparticles and released their therapeutic content at a slower rate (Figure 8), possibly due to the competing high hydrophilicity and low surface adsorption. Doxorubicin release from PECA-Dex6G8-Dox nanoparticles was rapid (similar to that of the free Doxorubicin from the dialysis-membrane bag used as control, Figure 8). PECA-Dex6G4-Dox nanoparticles had about $40 \%$ of their drug content released within about $8 \mathrm{~h}$, in comparison with about $95 \%$ of the drug released from PECA-Dex6G8 nanoparticles within the same timeframe. Overall, the release profiles demonstrated that, at the temperature and $\mathrm{pH}$ of the adopted experimental protocol, nanoparticles exhibited limited affinity for Doxorubicin hydrochloride; the release of Doxorubicin in its free base form has not been investigated.

\section{Figure 8.}

To assess the potential usefulness of these nanoparticles for imaging applications, the possibility of surface functionalization by chemically conjugating fluorescent labels suitable for carbohydrate substrates (such as N-methyl isatoic anhydride or tetramethyl Rhodamine-5carbonylazide [35,36]) was investigated. Conjugation of MIA to nanoparticles was evidenced by fluorescence measurements, NTA and confocal microscopy; DLS data indicated that the nature of the re-dispersion medium slightly affected both the size and PDI distribution of MIA-labelled nanoparticles (Table 4; also Supplementary material).

\section{Figure 9.}

Table 4. 
To identify a range of safe concentrations of the nanoparticles under consideration, a dose response study has been carried out and also the apparent toxicity induced by PECA was compared with that of poly(butyl cyanoacrylate) - or PBCA, a material widely investigated for nanoparticulate drug delivery applications [55] - by testing nanoparticles that had been prepared from the same materials but where ECA was replaced with BCA.

Experiments indicated that PBCA-Dex100G4 nanoparticles were well tolerated by bEnd3 cells at concentrations of up to $50 \mu \mathrm{g} / \mathrm{mL}$, while nanoparticles of PECA-Dex100G4 (1:1) and PECA-Dex100G4 (1:6) begin to exhibit toxic effects at concentrations $>25 \mu \mathrm{g} / \mathrm{mL}$ (Figure 10). This finding is consistent with earlier suggestions that the cytotoxicity of poly(alkyl acrylates) colloids (believed to be due to the formation of toxic formaldehyde via a minor degradation pathway[ 54,56]) correlates with their degradation rate, which is known to be inversely proportional to the length of the alkyl chain $[23,54,56]$. The faster degradation of PECA relative to that of longer-alkyl-chain PACA homologues may prove useful for applications where multiple dosing is required or for the delivery of vaccines or antigens with short optimal presentation and differentiation [57].

Literature reports have unveiled the complexity of the relationship between cytotoxic effect and cell type and also the effects of surface coatings on the particles. Lherm et al. have claimed that PECA nanoparticles are cytotoxic to L929 cells at concentration > 25 $\mu \mathrm{g} / \mathrm{mL}$ [23] while Pitaksuteepong et al. has reported adverse effects on cell viability at concentrations $>10$ $\mu \mathrm{g} / \mathrm{mL}$ [58]. Both PECA and PBCA particles have been reported to show identical cellular damage to mouse peritoneal macrophages [57]. Though Yordanov et al. suggested that PBCA nanospheres exert a low cytotoxic effect on A549 cells (viability >92\%)[20] and there was no noticeable induced cytotoxicity at the concentration of $75 \mu \mathrm{g} / \mathrm{mL}$ [24], membrane damage has been observed at $150 \mu \mathrm{g} / \mathrm{ml}$ [24]. Notably, while reports from clinical trials indicate that 
PACA degradation products do not induce any adverse effects of therapeutic significance [25], no clinical trials that are specific to either PECA or PBCA have been conducted.

Figure 10.

In summary, incubation for $24 \mathrm{~h}$ of mouse brain endothelial cells bEnd 3 with poly(alkyl cyanoacrylate)-alkylglyceryldextran (PECA-Dex100G4or PBCA-Dex100G4) nanoparticles revealed no significant toxicity induced by these nanoformulations at concentration $<25$ $\mu \mathrm{g} / \mathrm{mL}(\mathrm{p}=0.0010$, ANOVA $)$

\section{Conclusions}

Alkylglyceryl-modified dextrans, prepared by the functionalisation of dextran (MW 6 and $100 \mathrm{kDa}$ ) with alkyl oxiranes of systematically varied chain lengths (4 to 16), have been formulated into nanoparticles via controlled emulsion polymerization with either ethyl or butyl cyanoacrylates. The alkylglyceryl-modified dextran-poly(ethyl 2-cyanoacrylate) nanoparticles thus obtained were characterised by a unimodal average size in the range 100$500 \mathrm{~nm}$ and a negative zeta potential. Formulations of these nanoparticles in physiologically relevant media exhibited good stability.

Characterisation of alkylglyceryl dextrans by MALDI-TOF MS, TGA, DSC, GPC, FTIR and NMR indicated that the degree of substitution varied between 50 and $150 \%$ (as determined by ${ }^{1} \mathrm{H}-\mathrm{NMR}$ ) and that the hydrophilicity of the alkylglyceryl dextran decreased with increasing chain length of the progenitor alkyl glycerol; GPC data demonstrated that the polydispersity index of alkylglyceryl dextrans was lower than that of the corresponding precursor dextran irrespective of average molecular weight.

Alkylglyceryl-modified dextran-poly(ethyl 2-cyanoacrylate) nanoparticles were formulated and characterised by DLS, NTA, elemental analysis (CHN), NMR, FTIR, MALDI-TOF MS, 
SEM, DSC and TGA. In agreement with NMR data, CHN analysis calculations determined that the weight ratio of alkylglyceryl dextran to alkyl cyanoacrylate in the formulated nanoparticles was in the, formulation-dependent, range of 1:4 to 1:24.5. Studies involving the systematic variation of the alkylglyceryl chain length indicated that there is no direct relationship between chain length and nanoparticle size. Notably, nanoparticles that had been prepared from alkylglyceryl dextrans exhibited zeta potentials that were more negative than those of congeners that had been formulated from native dextrans. Autotitration experiments revealed that drug-free nanoparticles exhibit decreasing zeta potentials with decreasing $\mathrm{pH}$; average size appeared relatively stable across the $\mathrm{pH}$ range considered, with some of the tested nanoparticles exhibiting slightly smaller average size at lower $\mathrm{pH}$ values.

The nanoparticles were amenable to tagging with fluorophores (MIA; TMRCA) and to loading with a range of model drugs (Curcumin; Doxorubicin; Evans blue). Release studies from nanoparticles loaded with Evans blue have shown the rapid discharge of this hydrophilic model drug from the nanoparticulate matrix, however the release of Doxorubicin (or that of Curcumin) from nanoparticles was markedly slower. Tested against mouse bEnd3 brain endothelial cells, alkylglyceryl-modified dextran-poly(alkyl 2-cyanoacrylate) nanoparticles exhibited dose-dependent toxicity profiles: PBCA-Dex100G4 nanoparticles were found to be more biocompatible than PECA-Dex100G4 nanoparticles.

Acknowledgements. DI thanks the Nigerian Tertiary Education Trust Fund (TETFUND) and the University of Nigeria, Nsukka, for their financial assistance (PhD studentship).

\section{References}


1. Deeken, J. F. and Löscher, W. The blood-brain barrier and cancer: transporters, treatment, and Trojan horses. Clin. Cancer Res., 13(6), 1663-1674 (2007).

2. Gabathuler, R. Approaches to transport therapeutic drugs across the blood-brain barrier to treat brain diseases. Neurobiol. Dis., 37(1), 48-57 (2010).

3. Kreuter, J. Drug delivery to the central nervous system by polymeric nanoparticles: what do we know? Adv. Drug Delivery Rev., 71, 2-14 (2014).

4. Alyautdin, R., Khalin, I., Nafeeza, M. I., Haron, M. H., and Kuznetsov, D. Nanoscale drug delivery systems and the blood-brain barrier. Int. J. Nanomed., 9, 795-811 (2014).

5. Lo, E. H., Singhal, A. B., Torchilin, V. P., and Abbott, N. J. Drug delivery to damaged brain. Brain Res. Rev., 38(1), 140-148 (2001).

6. Rapoport, S. I. Osmotic opening of the blood-brain barrier: principles, mechanism, and therapeutic applications. Cell. Mol. Neurobiol., 20(2), 217-230 (2000).

7. Kroll, R. A and Neuwelt, E.A. Outwitting the blood-brain barrier for therapeutic purposes: osmotic opening and other means, Neurosurgery 42, 1083-1099 (1998).

8. Wagner, S., Zensi, A., Wien, S.L., Tschickardt, S.E., Maier, W., Vogel, T., et al. Uptake Mechanism of ApoE-Modified Nanoparticles on Brain Capillary Endothelial Cells as a Blood-Brain Barrier Model. PLoS ONE 7(3): e32568 (2012).

9. Ohtsuki, S. and Terasaki, T. Contribution of carrier-mediated transport systems to the blood-brain barrier as a supporting and protecting interface for the brain; importance for CNS drug discovery and development. Pharm. Res., 24(9):1745-58 (2007).

10. Solaro, R. Targeted delivery of proteins by nanosized carriers. J. Polym. Sci., Part A:Polym. Chem., 46(1), 1-11 (2008). 
11. Pişkin, E. Molecularly designed water soluble, intelligent, nanosize polymeric carriers. Int. J. Pharm., 277(1), 105-118 (2004).

12. Torchilin, V. (2012) Liposomes in drug delivery. In Fundamentals and Applications of Controlled Release Drug Delivery (Springer US), pp. 289-328.

13. Malam, Y., Loizidou, M., and Seifalian, A. M. Liposomes and nanoparticles: nanosized vehicles for drug delivery in cancer. Trends Pharmacol. Sci., 30(11): 592-599 (2009).

14. Schroeder, U., Sommerfeld, P., Ulrich, S., and Sabel, B. A. Nanoparticle technology for delivery of drugs across the blood-brain barrier. J. Pharm. Sci., 87(11), 1305-1307 (1998).

15. Otsuka, H., Nagasaki, Y., and Kataoka, K. PEGylated nanoparticles for biological and pharmaceutical applications. Adv. Drug Delivery Rev., 64:246-255 (2012).

16. Garcia-Garcia, E., Andrieux, K., Gil, S., and Couvreur, P. Colloidal carriers and bloodbrain barrier (BBB) translocation: a way to deliver drugs to the brain? Int. J. Pharm., 298(2):274-292 (2005).

17. Martins, S., Sarmento, B., Ferreira, D. C., and Souto, E.B. Lipid-based colloidal carriers for peptide and protein delivery-liposomes versus lipid nanoparticles. Int. J. Nanomed., 2(4):595-607 (2007).

18. Mattamal, G. J. US FDA perspective on the regulations of medical-grade polymers: cyanoacrylate polymer medical device tissue adhesives. Expert Rev. Med. Devices, 5(1): 4149 (2008).

19. Kreuter, J., Ramge, P., Petrov, V., Hamm, S., Gelperina, S.E., Engelhardt, B., Alyautdin, R., Von Briesen, H. and Begley, D.J. Direct evidence that polysorbate-80-coated poly (butylcyanoacrylate) nanoparticles deliver drugs to the CNS via specific mechanisms requiring prior binding of drug to the nanoparticles. Pharm. Res., 20(3), 409-416 (2003). 
20. Yordanov, G., Skrobanska, R., and Evangelatov, A. Entrapment of epirubicin in poly (butyl cyanoacrylate) colloidal nanospheres by nanoprecipitation: formulation development and in vitro studies on cancer cell lines. Colloids Surf. B, 92: 98-105 (2012).

21. Gulyaev, A.E., Gelperina, S.E., Skidan, I.N., Antropov, A.S., Kivman, G.Y., and Kreuter, J. Significant transport of doxorubicin into the brain with polysorbate 80-coated nanoparticles. Pharm. Res., 16(10), 1564-1569 (1999).

22. Olivier, J.C., Fenart, L., Chauvet, R., Pariat, C., Cecchelli, R. and Couet, W. Indirect evidence that drug brain targeting using polysorbate 80-coated polybutylcyanoacrylate nanoparticles is related to toxicity. Pharm. Res., 16(12):1836-1842 (1999).

23. Lherm, C., Muller, R.H., Puisieux, F., and Couvreur, P. Alkylcyanoacrylate drug carriers:II. cytotoxicity of cyanoacrylate nanoparticles with different alkyl chain-length. Int. J. Pharm., 84(1):13-22 (1992).

24. Vauthier, C., Dubernet, C., Fattal, E., Pinto-Alphandary, H. and Couvreur, P. Poly(alkylcyanoacrylates) as biodegradable materials for biomedical applications. Adv. Drug Delivery Rev., 55(4):519-548 (2003).

25. Kattan, J., Droz, J.P., Couvreur, P., Marino, J.P., Boutan-Laroze, A., Rougier, P., Brault, P., Vranckx, H., Grognet, J.M. and Morge, X. Phase I clinical trial and pharmacokinetic evaluation of doxorubicin carried by poly(isohexyl cyanoacrylate) nanoparticles. Invest. New Drugs, 10 (3):191-199 (1992).

26. Chauvierre, C., Labarre, D., Couvreur, P. and Vauthier, C. Radical emulsion polymerisation of alkylcyanoacrylates initiated by the redox system dextran-cerium(IV) under acidic aqueous conditions. Macromolecules, 36(16):6018-6027 (2003).

27. Kaul, G. and Amiji, M. Long-circulating poly (ethylene glycol)-modified gelatin nanoparticles for intracellular delivery. Pharm. Res., 19(7): 1061-1067 (2002). 
28. Jaulin, N., Appel, M., Passirani, C., Barratt, G. and Labarre, D. Reduction of the uptake by a macrophagic cell line of nanoparticles bearing heparin or dextran covalently bound to poly(methyl methacrylate). J. Drug Targeting, 8(3):165-172 (2000).

29. Easo, S.L. and Mohanan, P.V. Dextran stabilized iron oxide nanoparticles: Synthesis, characterization and in vitro studies. Carbohydr. Polym., 92(1):726-732 (2013).

30. Erdlenbruch, B., Jendrossek, V., Eibl, H. and Lakomek, M. Transient and controllable opening of the blood-brain barrier to cytostatic and antibiotic agents by alkylglycerols in rats. Exp. Brain Res., 135(3):417-422 (2000).

31. Marigny, K., Pedrono, F., Martin-Chouly, C.A., Youmine, H., Saiag, B. and Legrand, A.B. Modulation of endothelial permeability by 1-O-alkylglycerols. Acta Physiol. Scand., 176(4):263-268 (2002).

32. Erdlenbruch, B., Alipour, M., Fricker, G., Miller, D.S., Kugler, W., Eibl, H. and Lakomek, M. Alkylglycerol opening of the blood-brain barrier to small and large fluorescence markers in normal and C6 glioma-bearing rats and isolated rat brain capillaries. Br. J. Pharmacology, 140(7):1201-1210 (2003).

33. Hülper, P., Veszelka, S., Walter, F.R., Wolburg, H., Fallier-Becker, P., Piontek, J., Blasig, I.E., Lakomek, M., Kugler, W. and Deli, M.A. Acute effects of short-chain alkylglycerols on blood-brain barrier properties of cultured brain endothelial cells. $\mathrm{Br}$. J.

Pharmacology, 169(7):1561-1573 (2013).

34. Toman, P., Lien, C.F., Ahmad, Z., Dietrich, S., Smith, J.R., An, Q., Molnár É, Pilkington G.J., Górecki, D.C., Tsibouklis, J. and Barbu, E. Nanoparticles of alkylglyceryl-dextran-poly (lactic acid) for drug delivery to the brain: Preparation and in vitro investigation. Acta Biomater. 23:250-262 (2015). 
35. DeAngelis, P.L. Polysaccharide labeling with N-methylisatoic anhydride: Generation of ultraviolet chromophores and blue fluorophores. Anal. Biochem., 284(1):167-169 (2000).

36. Wan, C.P.L., Letchford, K., Jackson, J.K. and Burt, H.M. The combined use of paclitaxelloaded nanoparticles with a low-molecular-weight copolymer inhibitor of P-glycoprotein to overcome drug resistance. Int. J. Nanomed., 8:379-391 (2013).

37. Arranz, F., Roman, J.S. and Sanchezchaves, M. C-13 NMR-study of the selectivity in the modification of dextran with ethyl chloroformate. Macromolecules, 20(4): 801-806 (1987).

38. Covis, R., Ladaviere, C., Desbrieres, J., Marie, E. and Durand, A. Synthesis of watersoluble and water-insoluble amphiphilic derivatives of dextran in organic medium. Carbohydr. Polym., 95(1):360-365 (2013).

39. Bashari, M., Lagnika, C., Ocen, D., Chen, H., Wang, J., Xu, X., and Jin, Z. Separation and characterization of dextran extracted from deteriorated sugarcane. Int.J. Biol. Macromol., 59:246-54 (2013).

40. Siddiqui, N.N., Aman, A., Silipo, A., Qader, S.A.U., Molinaro, A. Structural analysis and characterization of dextran produced by wild and mutant strains of Leuconostoc mesenteroides. Carbohydr. Polym., 99:331-338 (2014).

41. Vollmer, A., Voiges, K., Bork, C., Fiege, K., Cuber, K. and Mischnick, P. Comprehensive analysis of the substitution pattern in dextran ethers with respect to the reaction conditions. Anal. Bioanal. Chem., 395(6):1749-1768 (2009).

42. De Belder, A.N. Dextran. Amershaw Bioscience. Report No. 18-1166-12 (2003).

43. Gil, E.C., Colarte, A.I., El Ghzaoui, A., Durand, D., Delarbre, J.L. and Bataille, B. A sugar cane native dextran as an innovative functional excipient for the development of pharmaceutical tablets. Eur. J. Pharm. Biopharm., 68(2):319-329 (2008). 
44. Stenekes, R.J.H., Talsma, H. and Hennink, W.E. Formation of dextran hydrogels by crystallisation. Biomaterials, 22(13):1891-1898 (2001).

45.Tang, M., Dou, H. and Sun, K. One-step synthesis of dextran-based stable nanoparticles assisted by self-assembly. Polymer, 47(2):728-734 (2006).

46. Bertholon-Rajot, I., Labarre, D., and Vauthier, C. Influence of the initiator system, cerium-polysaccharide, on the surface properties of poly(isobutyl cyanoacrylate) nanoparticles. Polymer, 46(4), 1407-1415 (2005).

47. Pirker, S., Kruse, J., Noe, C., Langer, K., Zimmer, A. and Kreuter, J. Characterisation of polybutyleyanoacrylate nanoparticles. Part II: determination of polymer content by NMRanalysis. Int. J. Pharm., 128(1):189-195 (1996).

48. Karas, M., Bahr, U., Strupat, K., Hillenkamp, F., Tsarbopoulos, A. and Pramanik, B.N. Matrix dependence of metastable fragmentation of glycoproteins in MALDI TOF mass spectrometry. Anal. Chem., 67(3):675-679 (1995).

49. Harvey, D.J. Matrix-assisted laser desorption/ionisation mass spectrometry of carbohydrates. Mass Spectrom. Rev., 18(6):349-450 (1999).

50. Hung, W.T., Wang, S.H., Chen, Y.T., Yu, H.M., Chen, C.H., Yang, W.B. MALDI-TOF MS analysis of native and permethylated or benzimidazole-derivatized polysaccharides. Molecules, 17(5):4950-4961 (2012).

51. Qi, J., Yao, P., He, F., Yu, C. and Huang, C. Nanoparticles with dextran/chitosan shell and BSA/chitosan core--Doxorubicin loading and delivery. Int. J. Pharm., 393(1):177-185 (2010).

52. O'Sullivan, C. and Birkinshaw, C. Hydrolysis of poly (n-butylcyanoacrylate) nanoparticles using esterase. Polym. Degrad. Stab., 78(1):7-15 (2002). 
53. Muller, R.H., Lherm, C., Herbort, J., Blunk, T. and Couvreur, P. Alkylcyanoacrylate drug carriers - 1 - physicochemical characterisation of nanoparticles with different alkyl chainlength. Int. J. Pharm., 84(1):1-11 (1992).

54. Scherer, D., Robinson, J.R. and Kreuter, J. Influence of enzymes on the stability of polybutylcyanoacrylate nanoparticles. Int. J. Pharm., 101(1):165-168 (1994).

55. Chaudhari, K.R., Ukawala, M., Manjappa, A.S., Kumar, A., Mundada, P.K., Mishra, A.K., Mathur, R., Mönkkönen, J. and Murthy, R.S.R. Opsonization, biodistribution, cellular uptake and apoptosis study of PEGylated PBCA nanoparticle as potential drug delivery carrier. Pharm. Res., 29(1):53-68 (2012).

56. Müller, R.H., Lherm, C., Herbert, J., and Couvreur, P. In vitro model for the degradation of alkylcyanoacrylate nanoparticles. Biomaterials, 11(8): 590-595 (1990).

57. Cruz, T., Gaspar, R., Donato, A. and Lopes, C. Interaction between polyalkylcyanoacrylate nanoparticles and peritoneal macrophages: MTT metabolism, NET reduction, and NO production. Pharm. Res., 14(1):73-79 (1997).

58. Pitaksuteepong, T., Davies, N.M., Baird, M., and Rades, T. Uptake of antigen encapsulated in polyethylcyanoacrylate nanoparticles by D1-dendritic cells. Pharmazie, 59(2):134-142 (2004). 


\section{List of tables}

Table 1. Dextrans and modified dextrans investigated in this study. The degree of substitution (DS) was determined from ${ }^{1} H$-NMR data; the onset-of-degradation temperature and percentage residual mass at $450^{\circ} \mathrm{C}$ were determined by TGA.

Table 2. Summary of DSC data for both native and modified dextrans.

Table 3. Elemental composition of PECA-alkylglyceryl dextran nanoparticles (found and calculated).

Table 4. The effect of redispersion media on the size and size distribution (as measured by DLS) of PECA-Dex100G8 nanoparticles fluorescently labelled with MIA.

Table 1. Dextrans and modified dextrans investigated in this study. The degree of substitution (DS) was determined from ${ }^{1} \mathrm{H}$-NMR data; the onset-of-degradation temperature and percentage residual mass at $450^{\circ} \mathrm{C}$ were determined by TGA.

\begin{tabular}{|l|l|l|l|l|l|}
\hline no & & Material & $\begin{array}{l}\text { DS (\%) } \\
\left({ }^{1} \mathrm{H}-\mathrm{NMR}\right)\end{array}$ & $\begin{array}{l}\text { Degradation } \\
\text { onset }\left({ }^{\circ} \mathrm{C}\right)\end{array}$ & $\begin{array}{l}\text { Residual mass } \\
\text { at } 450^{\circ} \mathrm{C}(\%)\end{array}$ \\
\hline 1 & & Dex6 & 0 & 300.6 & 16.03 \\
\hline 2 & & Dex6G4 & 87.7 & 313.9 & 2.27 \\
\hline 3 & & Dex6G8 & 114.94 & 328.6 & 10.70 \\
\hline 4 & & Dex6G12 & 54.35 & 298.0 & 6.55 \\
\hline 5 & & Dex6G16 & 133.33 & 233.3 & 7.89 \\
\hline 6 & & Dex100 & 0 & 290.3 & 19.07 \\
\hline 7 & & Dex100G4 & 68.49 & 310.7 & 12.11 \\
\hline 8 & & Dex100G8 & 64.91 & 293.5 & 14.33 \\
\hline 9 & & Dex100G12 & 67.56 & 301.9 & 2.55 \\
\hline 10 & & Dex100G16 & 144.92 & 308.9 & 5.48 \\
\hline
\end{tabular}


Table 2. Summary of DSC data for both native and modified dextrans.

\begin{tabular}{|l|l|l|l|l|l|}
\hline & \multicolumn{4}{|l|}{$1^{\text {st }}$ run } & \multicolumn{2}{l|}{${ }^{\text {nd }}$ run } \\
\hline & $\begin{array}{l}\text { Endotherm } \\
\text { peak area }(\mathrm{J} / \mathrm{g})\end{array}$ & $\begin{array}{l}1^{\text {st }} \mathrm{T}_{\mathrm{g}} \\
\left({ }^{\circ} \mathrm{C}\right)\end{array}$ & $\begin{array}{l}\mathrm{Cp} \\
\left(\mathrm{Jg}^{-1} \mathrm{~K}^{-1}\right)\end{array}$ & $\begin{array}{l}2^{\text {nd }} \mathrm{T}_{\mathrm{g}} \\
\left({ }^{\circ} \mathrm{C}\right)\end{array}$ & $\begin{array}{l}\mathrm{Cp} \\
\left(\mathrm{Jg}^{-1} \mathrm{~K}^{-1}\right)\end{array}$ \\
\hline Dex6 & 204.2 & 48.6 & 0.007 & 198.4 & 0.428 \\
\hline Dex6G4 & 122.7 & 45.5 & 0.026 & 175.7 & 0.178 \\
\hline Dex6G8 & 75.47 & 49.5 & 0.036 & - & - \\
\hline Dex6G12 & 73.94 & 42.2 & 0.008 & - & - \\
\hline Dex6G14 & 61.37 & 46.0 & 0.001 & - & - \\
\hline Dex6G16 & 18.44 & 47.1 & 0.022 & - & - \\
\hline Dex100 & 229 & 58.2 & 0.028 & 216.4 & 0.384 \\
\hline Dex100G4 & 169.5 & 50.2 & 0.003 & 183.4 & 0.052 \\
\hline Dex100G8 & 102.9 & 50.3 & 0.036 & - & - \\
\hline Dex100G12 & 86.34 & 50.0 & 0.024 & - & - \\
\hline Dex100G14 & 39.1 & 55.6 & 0.006 & - & - \\
\hline Dex100G16 & 0 & 68.2 & 0.017 & - & - \\
\hline
\end{tabular}


Table 3. Elemental composition of PECA-alkylglyceryl dextran nanoparticles (found and calculated).

\begin{tabular}{|c|c|c|c|c|c|c|c|c|c|c|}
\hline \multirow[t]{2}{*}{ S/No } & \multirow[t]{2}{*}{ Material } & \multicolumn{2}{|l|}{ Carbon } & \multicolumn{2}{|c|}{ Hydrogen } & \multicolumn{2}{|l|}{ Nitrogen } & \multirow{2}{*}{$\begin{array}{l}\text { Oxygen } \\
(\% ; \\
100 \mathrm{CHN})\end{array}$} & \multirow{2}{*}{$\begin{array}{l}\text { PECA } \\
(\% \mathrm{w})\end{array}$} & \multirow{2}{*}{$\begin{array}{l}\text { Dex-G } \\
(\% \mathrm{w})\end{array}$} \\
\hline & & $\begin{array}{l}\text { Found } \\
\text { (av\%C) }\end{array}$ & $\begin{array}{l}\text { Calc. } \\
\mathrm{C} \%\end{array}$ & $\begin{array}{l}\text { Found } \\
(\mathrm{av \% H})\end{array}$ & $\begin{array}{l}\text { Calc. } \\
\% \mathrm{H}\end{array}$ & $\begin{array}{l}\text { Found } \\
(\text { av.\%N) }\end{array}$ & $\begin{array}{l}\text { Calc. } \\
\% \mathrm{~N}\end{array}$ & & & \\
\hline 1 & $\begin{array}{l}\text { PECA } \\
\text { Dex6G4 }\end{array}$ & 55.94 & 57.22 & 5.77 & 5.83 & 10.33 & 10.33 & 27.96 & 92.25 & 7.75 \\
\hline 2 & $\begin{array}{l}\text { PECA } \\
\text { Dex6G8 }\end{array}$ & 56.31 & 58.03 & 6.34 & 6.51 & 8.65 & 8.65 & 28.70 & 80.38 & 19.62 \\
\hline 3 & $\begin{array}{l}\text { PECA } \\
\text { Dex6G12 }\end{array}$ & 56.31 & 57.61 & 5.89 & 5.88 & 10.41 & 10.41 & 27.39 & 94.34 & 5.66 \\
\hline 4 & $\begin{array}{l}\text { PECA } \\
\text { Dex6G16 }\end{array}$ & 56.95 & 59.36 & 6.45 & 6.61 & 9.13 & 9.133 & 27.47 & 88.09 & 11.91 \\
\hline 5 & $\begin{array}{l}\text { PECA } \\
\text { Dex100G4 }\end{array}$ & 56.07 & 57.17 & 5.81 & 5.79 & 10.41 & 10.41 & 27.71 & 92.99 & 7.01 \\
\hline 6 & $\begin{array}{l}\text { PECA } \\
\text { Dex100G4A }\end{array}$ & 56.81 & 57.29 & 5.67 & 5.75 & 10.62 & 10.62 & 26.90 & 94.84 & 5.159 \\
\hline 7 & $\begin{array}{l}\text { PECA } \\
\text { Dex100G8 }\end{array}$ & 56.22 & 57.51 & 5.73 & 5.78 & 10.67 & 10.67 & 27.38 & 95.92 & 4.079 \\
\hline 8 & $\begin{array}{l}\text { PECA } \\
\text { Dex100G12 }\end{array}$ & 56.35 & 57.69 & 5.82 & 5.83 & 10.63 & 10.63 & 27.19 & 96.09 & 3.91 \\
\hline 9 & $\begin{array}{l}\text { PECA } \\
\text { Dex100G16 }\end{array}$ & 57.22 & 59.78 & 6.58 & 6.80 & 8.78 & 8.78 & 27.42 & 86.07 & 13.93 \\
\hline 10 & $\begin{array}{l}\text { PECA } \\
\text { Dex100G16A }\end{array}$ & 57.99 & 59.63 & 6.35 & 6.72 & 8.94 & 8.94 & 26.73 & 87.05 & 12.95 \\
\hline
\end{tabular}


Table 4. The effect of redispersion media on the size and size distribution (as measured by DLS) of PECA-Dex100G8 nanoparticles fluorescently labelled with MIA.

\begin{tabular}{|l|l|l|}
\hline Redispersion media & Z-av.d $(\mathrm{nm})$ & PDI \pm SD \\
\hline water & $141.4 \pm 1.0$ & $0.241 \pm 0.006$ \\
\hline $\mathrm{NaCl}(10 \mathrm{mM})$ & $133.2 \pm 1.6$ & $0.224 \pm 0.009$ \\
\hline $\mathrm{PBS}(\mathrm{pH} 7.4)$ & $226.0 \pm 5.3$ & $0.467 \pm 0.011$ \\
\hline PBS $(\mathrm{pH} 7.4 ; 0.2 \mu \mathrm{m}$ PES filter) & $134.6 \pm 0.4$ & $0.221 \pm 0.007$ \\
\hline
\end{tabular}




\section{List of figures}

Figure 1. FTIR-ATR spectra of dextran (Dex) and alkyl glyceryl dextrans (Dex4, Dex8).

Figure 2. Typical TG and DTG (first derivative) curves for A) Dex6 and Dex6G16, and B) Dex100 and Dex100G16. C) Water content (measured from the first-stage mass loss) as a function of chain length (Dex100 and Dex6 modifications). D) Typical DSC thermogram of dextran and its modifications (here Dex100; green curve represents $1^{\text {st }}$ heating run; blue curve represents $2^{\text {nd }}$ heating run).

Figure 3. ${ }^{1} \mathrm{H}$ NMR spectra of (A) PECADex100G8 nanoparticles and (B) pure PECA; inset

(C) shows the generic structure of alkylglyceryl-dextran-poly(ethyl cyanoacrylate) copolymers.

Figure 4. MALDI TOF spectra of: (A) Dex6G4 and (B) PECADex6G4 nanoparticles (CHCA matrix).

Figure 5. SEM (A) and TEM (B) images of PECA-Dex100G4 nanoparticles.

Figure 6. The effect of $\mathrm{pH}$ on the main characteristics of nanoparticles $(0.25 \mathrm{mg} / \mathrm{mL})$ for: $(A)$ PECA-only nanoparticles; (B) PECA-Dex6G4 nanoparticles; (C) PECA-Dex6G16 nanoparticles.

Figure 7. The time-dependent effect of enzymatic activity (0-1220 units of esterase) on the degradation of PECA-Dex100G4 nanoparticles: (A) size (as measured by DLS); and (B) PDI measurements.

Figure 8. Cumulative drug release profiles from Doxorubicin hydrochloride-loaded PECADex6G4 and PECA-Dex6G8 nanoparticles ( $n=3$; bars represent $\pm S D)$. 
Figure 9. Schematic representation of the conjugation reactions employed for the fluorescent tagging of: A) PECA-Dex100G8 nanoparticles, via reaction with $N$-methylisatoic anhydride (MIA); B) PECA-Dex6G12 nanoparticles, via reaction with Tetramethyl Rhodamine-5carbonylazide.

Figure 10. Relative viability of bEnd3 cells incubated with PBCA/PECA alkylglyceryl dextran nanoparticles at various concentrations $(10 \mu \mathrm{g} / \mathrm{mL} ; 25 \mu \mathrm{g} / \mathrm{mL} ; 50 \mu \mathrm{g} / \mathrm{mL} ; 100 \mu \mathrm{g} / \mathrm{mL})$ for 24 $h$ (MTT assay; media blank used as negative control; Triton-X100 as positive control; $n=3$; $\pm S D$; e.g. PECA(1:1)10 denotes PECA-Dex100G4(1:1) nanoparticles at $10 \mu \mathrm{g} / \mathrm{mL}$ conc., where 1:1 (or 1:6) indicates different ratios ECA : modified dextran at the preparation stage). 

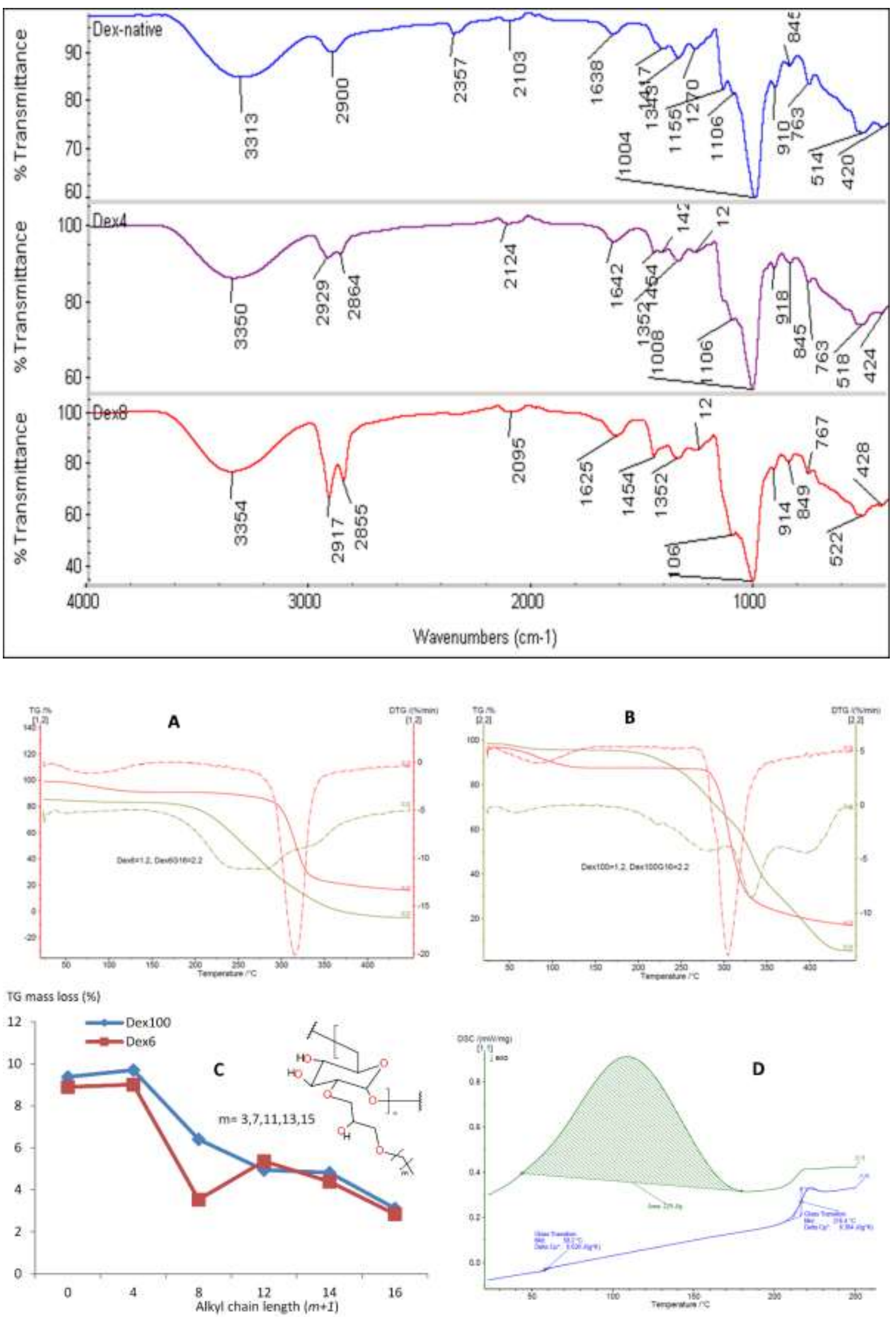


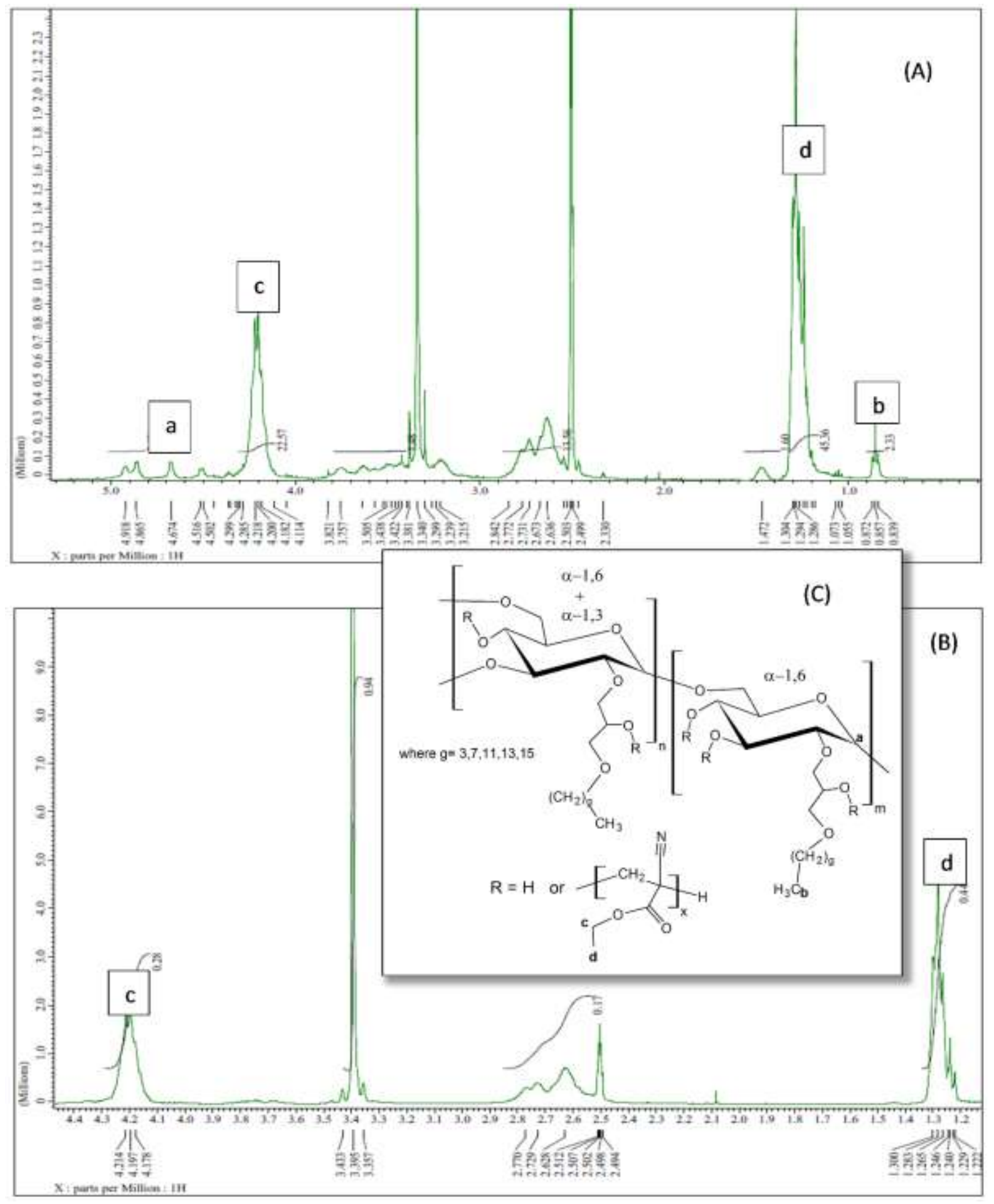



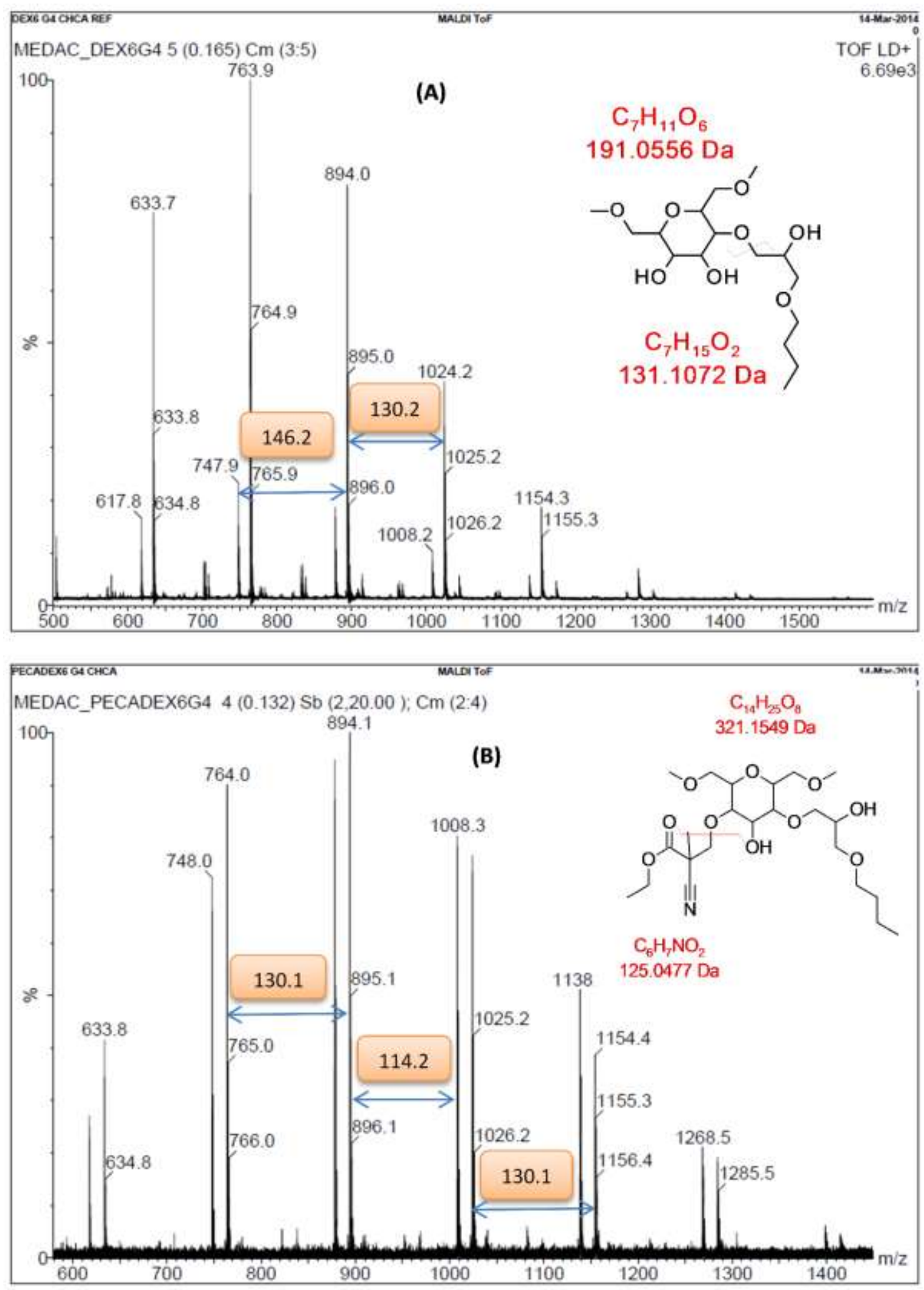


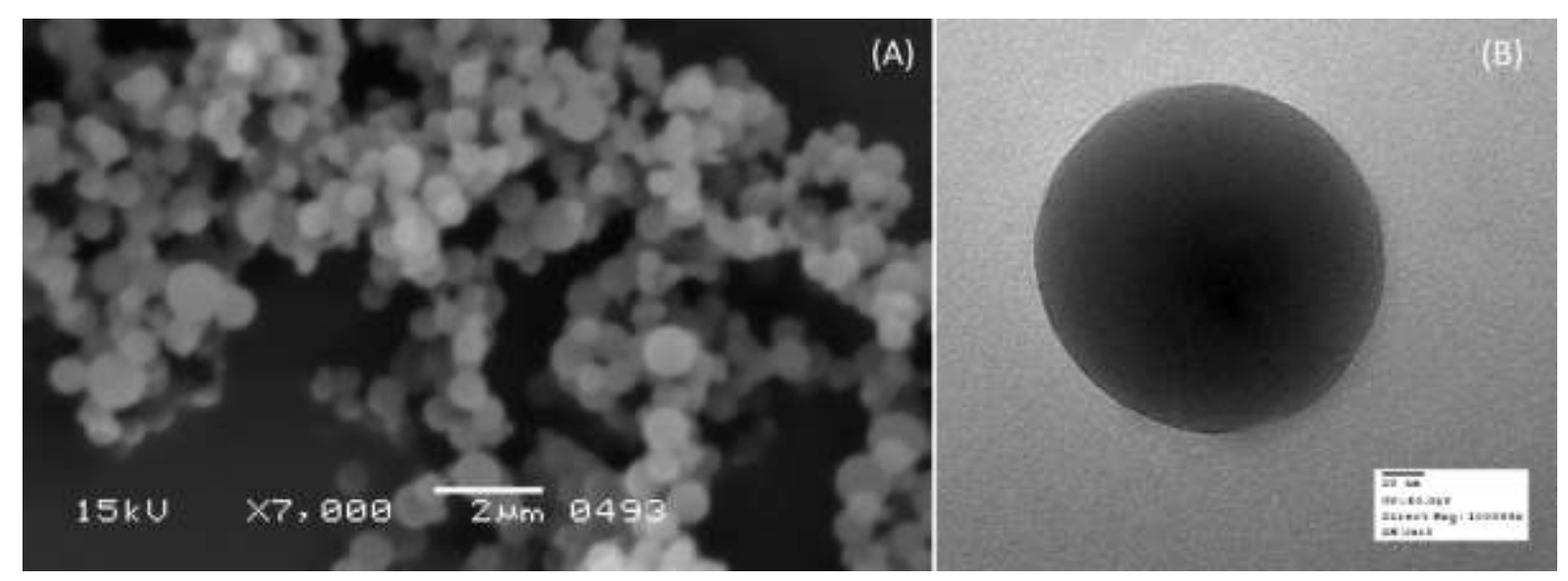



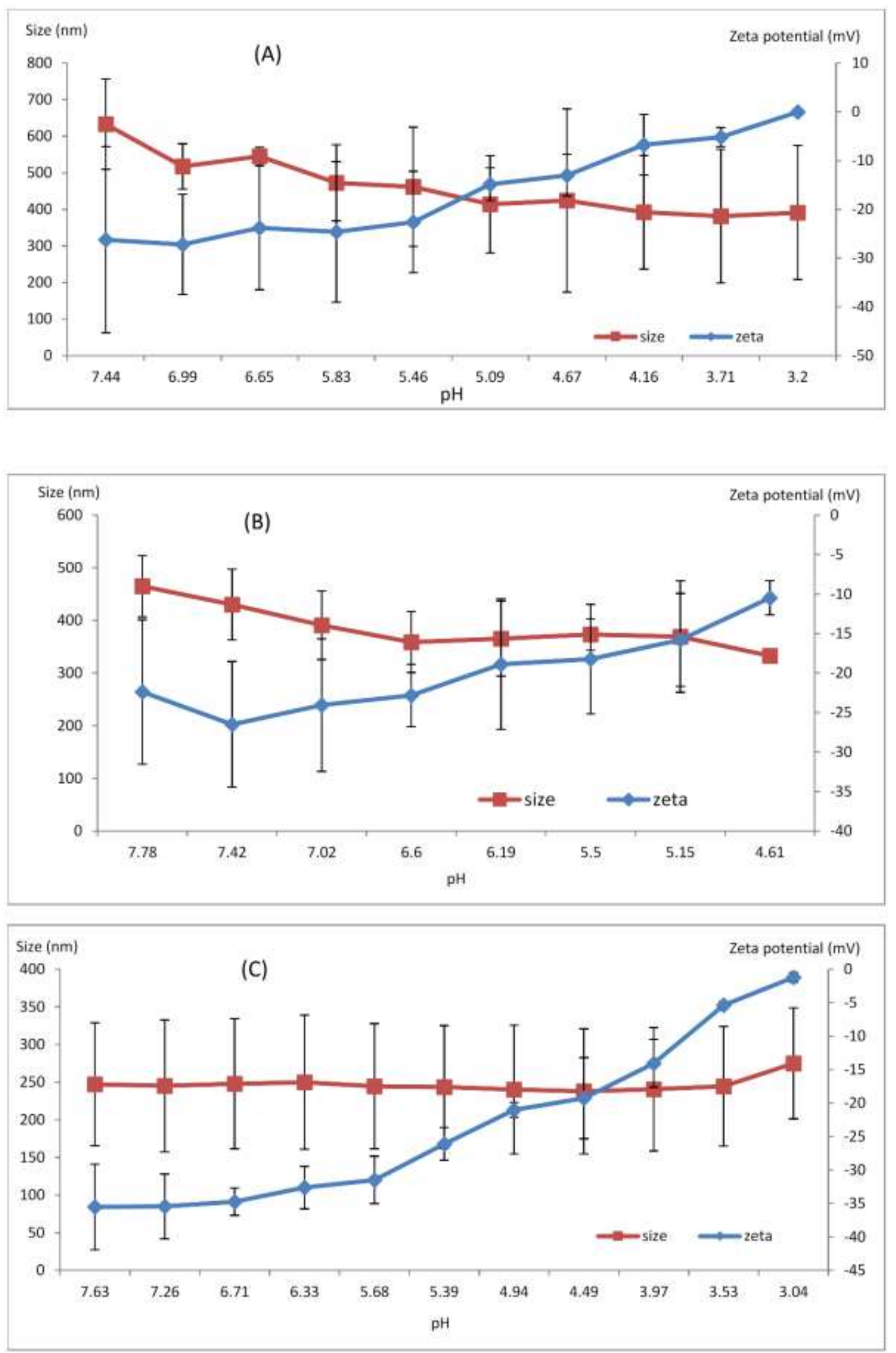

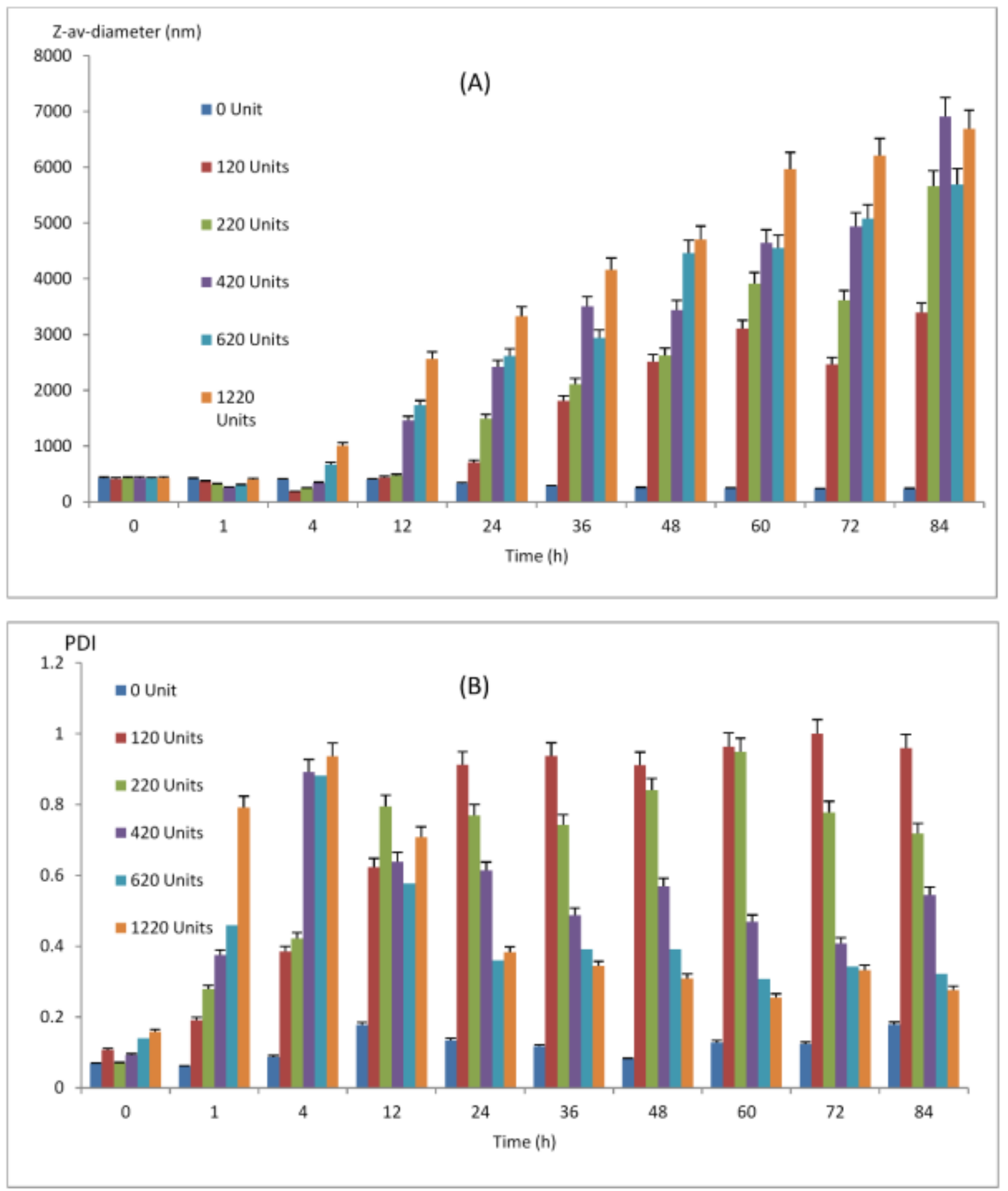


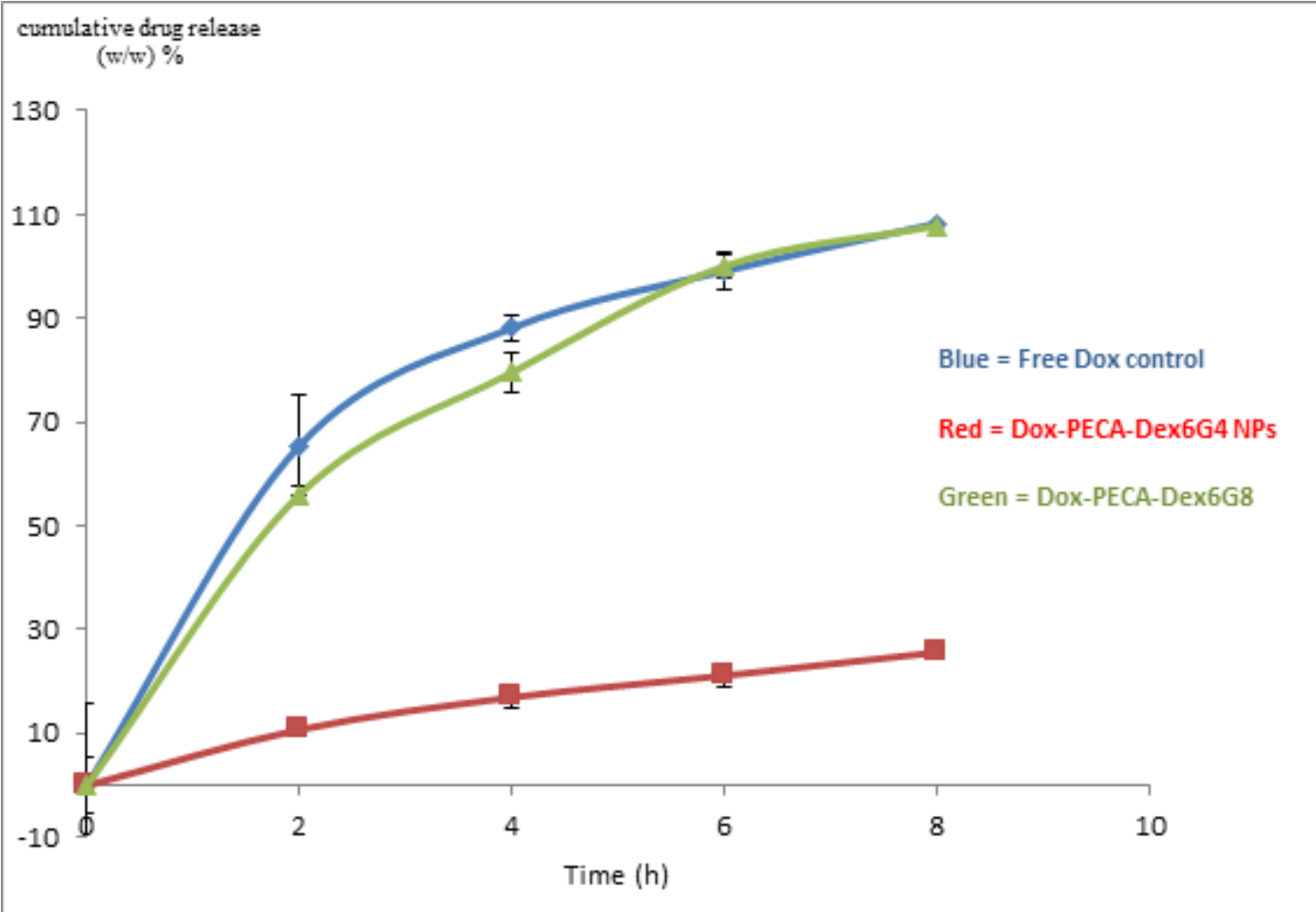


(A)<smiles>Cn1c(=O)oc(=O)c2ccccc21</smiles>

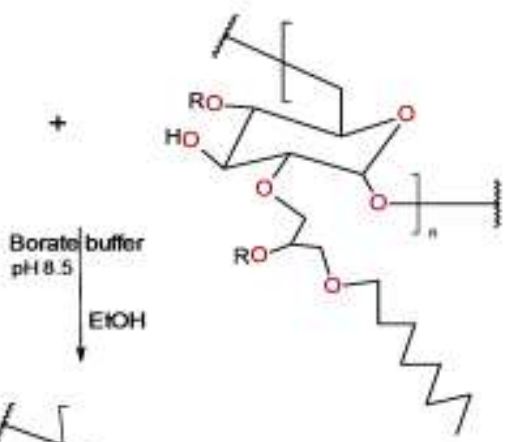

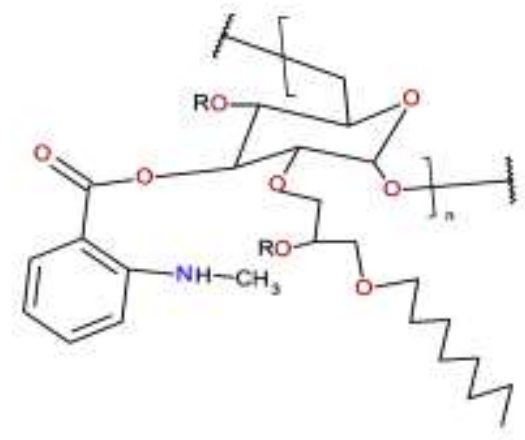<smiles>CCOC(=O)C(C)(C)C(C)C</smiles>

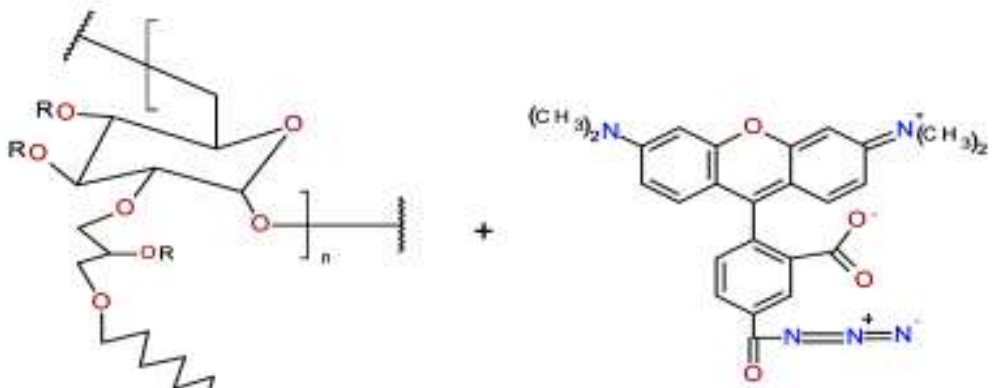

(B)
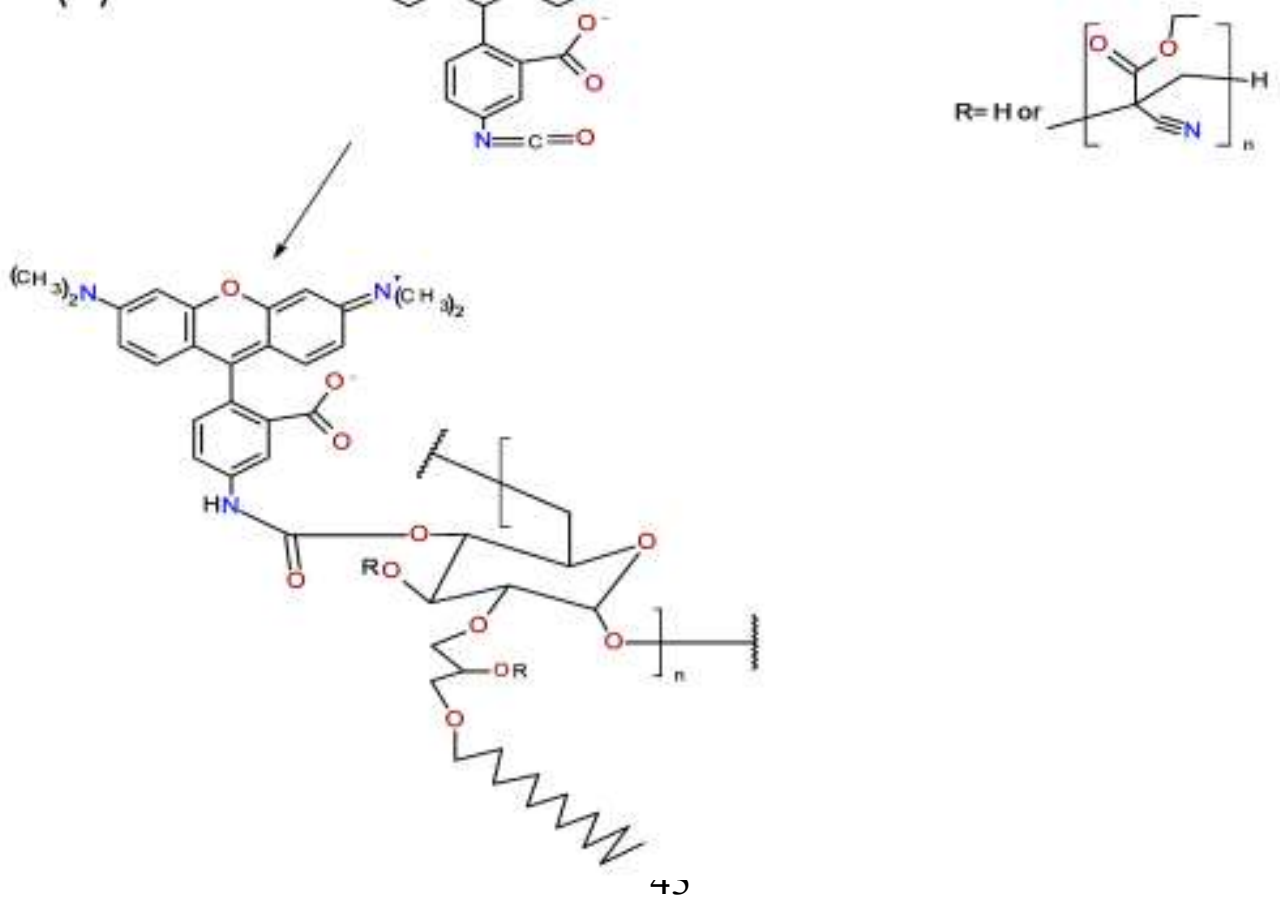

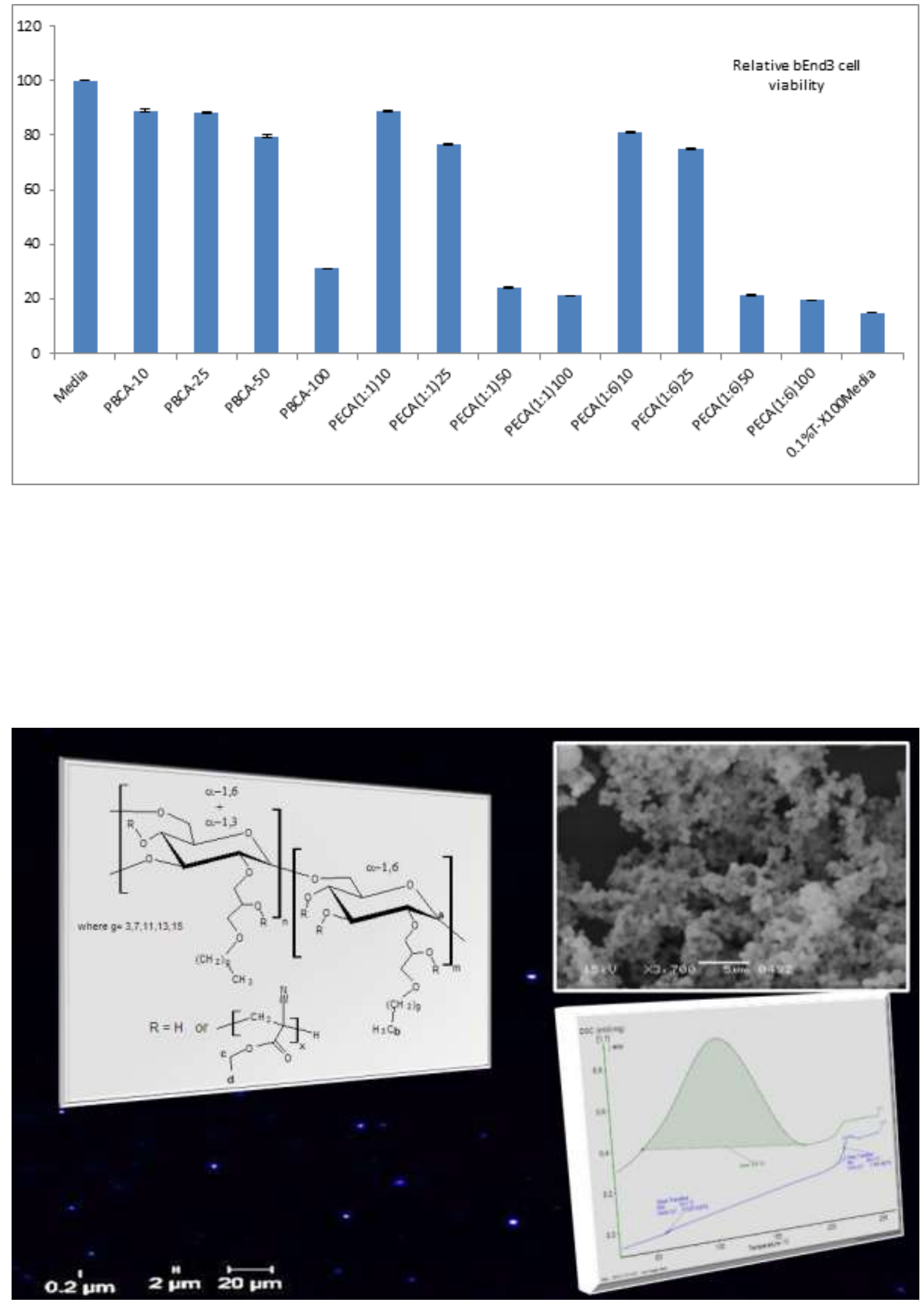


\section{Supplementary information}

\section{S-1. Biodegradation studies}

Table S1: The enzyme activity, mass and volume of the stock solution (conc. $12 \mathrm{mg} / \mathrm{mL}$ ) used for the biodegradability study of PECA-Dex100G4 nanoparticles

\begin{tabular}{|l|l|l|l|l|l|l|}
\hline Units of enzyme & 0 & 120 & 220 & 420 & 620 & 1220 \\
\hline Enzyme mass (mg) & 0 & 7.06 & 12.94 & 24.71 & 36.47 & 71.75 \\
\hline $\begin{array}{l}\text { Volume of enzyme } \\
\text { solution used (mL) }\end{array}$ & 0 & 0.59 & 1.08 & 2.06 & 3.04 & 5.98 \\
\hline
\end{tabular}

\section{S-2. MTT assay}

MTT (3-(4,5-Dimethylthiazol-2-yl)-2,5-diphenyl tetrazolium bromide) assay protocol

The MTT working solution was prepared by allowing a solution of MTT in DMEM (5 $\mathrm{mg} / \mathrm{mL}$; kept in the dark at $2-8^{\circ} \mathrm{C}$ until needed) to reach $37^{\circ} \mathrm{C}$ and a steady state concentration of $5 \% \mathrm{CO}_{2}$ before dilution (1:5) with DMEM. BEnd3 cells $(20,000)$ were seeded (in triplicate) into each of a 96 well plate containing $200 \mu$ l of normal media (DMEM containing $10 \%$ fetal bovine serum, FBS) and incubated for $24 \mathrm{~h}$. After this time, in each well were added $20 \mu \mathrm{l}$ of each nanoformulation and of alkylglyceryl dextran formulations dispersed in PBS at specified concentrations prior to incubation for $24 \mathrm{~h}$ at $37^{\circ} \mathrm{C}\left(5 \% \mathrm{CO}_{2}\right)$. After this time, to each well was added MTT working solution $(50 \mu \mathrm{l})$ and the mixture was incubated for $2 \mathrm{~h}$ at $37^{\circ} \mathrm{C}\left(5 \% \mathrm{CO}_{2}\right)$. The media was then removed from each well, replaced with $100 \mu \mathrm{l}$ of DMSO and this mixture was agitated gently until the formazan crystals had dissolved. Each plate was inserted into the plate reader and the absorbance was read at $570 \mathrm{~nm}$. The viability of cells was calculated (Equation 5.1) as percentage relative to PBS (negative control); Triton-X100 provided the positive control.

Re lative.cell.viability $\%=\frac{\text { A.test }}{\text { A.control }} * 100$ (eq. 5.1) 


\section{S-3. GPC}

Table S3: Calibration - pullulan standards

\begin{tabular}{|l|l|l|l|l|l|l|l|l|}
\hline & $\begin{array}{l}\text { Retention } \\
\text { Time /min }\end{array}$ & $\begin{array}{l}\text { Elution } \\
\text { Vol. (mL) }\end{array}$ & Mol Wt & $\begin{array}{l}\text { Log (Mol } \\
\mathbf{W t})\end{array}$ & $\begin{array}{l}\text { Calculated } \\
\text { Weight }\end{array}$ & $\begin{array}{l}\text { \% } \\
\text { Residual }\end{array}$ & $\begin{array}{l}\text { Standard } \\
\text { Type }\end{array}$ & $\begin{array}{l}\text { Relative } \\
\text { Weight }\end{array}$ \\
\hline 1 & 9.549 & 9.549 & 805000 & 5.905796 & 790018 & 1.896 & Narrow & 1.00 \\
\hline 2 & 10.413 & 10.413 & 366000 & 5.563481 & 383256 & -4.502 & Narrow & 1.00 \\
\hline 3 & 11.281 & 11.281 & 210000 & 5.322219 & 206578 & 1.657 & Narrow & 1.00 \\
\hline 4 & 12.219 & 12.219 & 113000 & 5.053078 & 109750 & 2.961 & Narrow & 1.00 \\
\hline 5 & 13.295 & 13.295 & 48800 & 4.688420 & 49454 & -1.322 & Narrow & 1.00 \\
\hline 6 & 14.188 & 14.188 & 21700 & 4.336460 & 21831 & -0.602 & Narrow & 1.00 \\
\hline 7 & 14.865 & 14.865 & 10000 & 4.000000 & 10136 & -1.338 & Narrow & 1.00 \\
\hline 8 & 15.271 & 15.271 & 6000 & 3.778151 & 5914 & 1.459 & Narrow & 1.00 \\
\hline
\end{tabular}




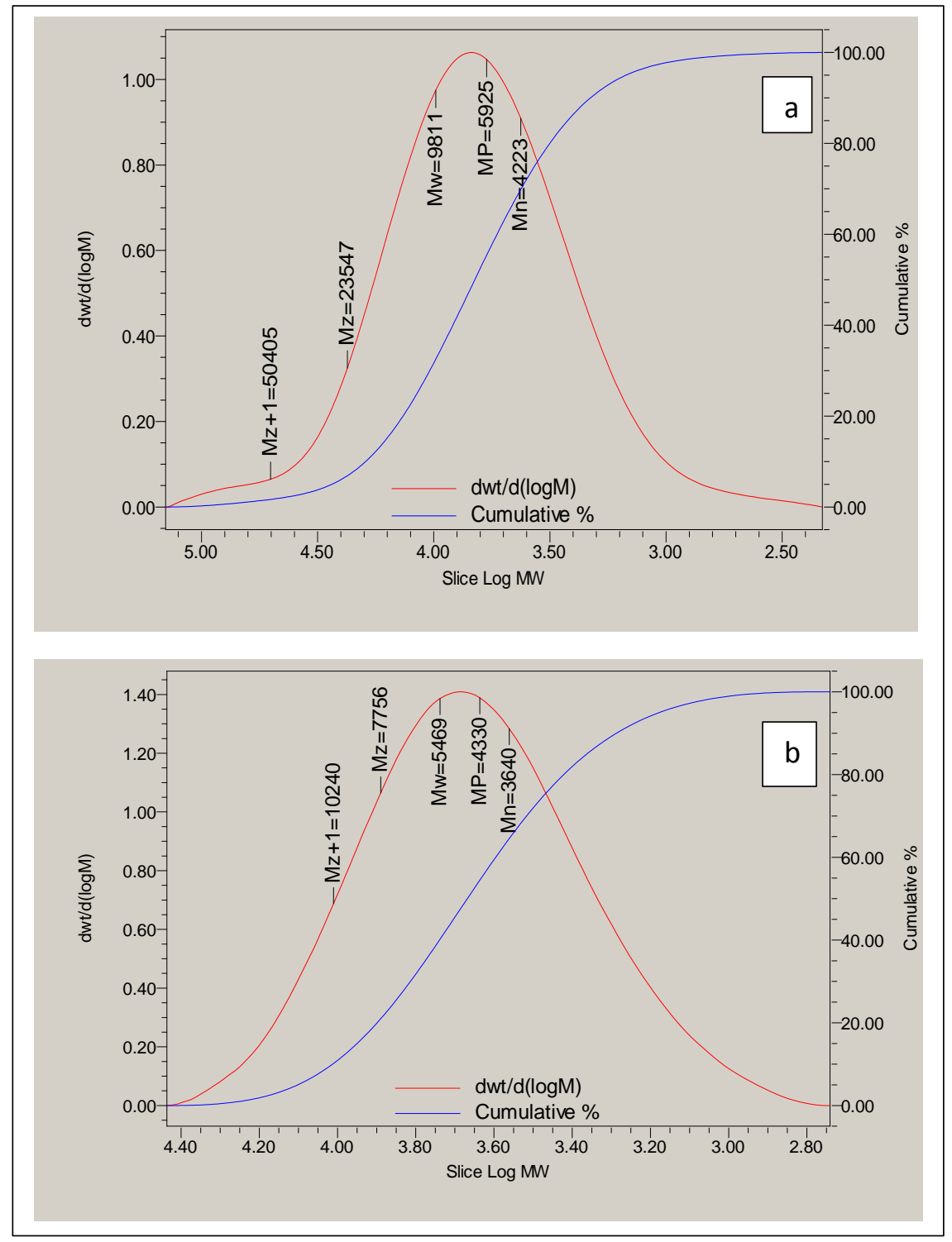

GPC chromatogram of (a) native dextran (Dex6) and (b) akyl glyceryl dextran (Dex6G4)

Pullulan standard curve equation

\begin{tabular}{|l|l|l|l|l|}
\hline & $\mathbf{R}$ & $\mathbf{R}^{\wedge} \mathbf{2}$ & Standard Error & Equation \\
\hline 1 & 0.999902 & 0.999804 & $1.407507 \mathrm{e}-002$ & $\begin{array}{l}\text { Log Mol Wt }=2.24 \mathrm{e}+001-3.87 \mathrm{e}+000 \mathrm{~T} \mathrm{~T}^{\wedge} 1+3.08 \mathrm{e}-001 \mathrm{~T}^{\wedge} 2-8.84 \mathrm{e}- \\
003 \mathrm{~T} \mathrm{~T}^{\wedge} 3\end{array}$ \\
\hline
\end{tabular}




\section{S-4. Elemental analysis}

Equations used to calculate the polymer mass composition from the results of elemental analysis

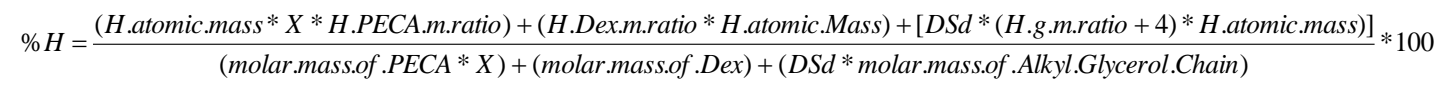

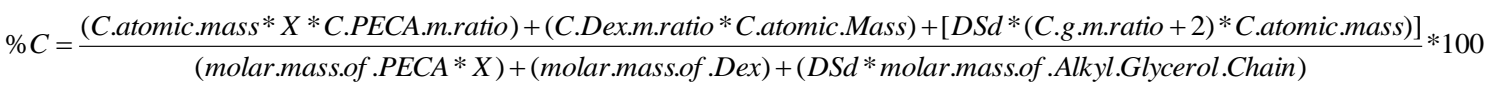

$\% N=\frac{(\text { N.atomic.mass } * X * N . P E C A . m . r a t i o)}{(\text { molar.mass.of } . P E C A * X)+(\text { molar.mass.of.Dex })+(D S d * \text { molar.mass.of .Alkyl.Glycerol.Chain })} * 100$

$\%$ PECA $=\frac{(\text { m.mass.of.PECA } * X)}{(\text { molar.mass.of } . P E C A * X)+(\text { molar.mass.of } . \text { Dex })+(D S d * \text { molar.mass.of } . \text { Alkyl.Glycerol.Chain })} * 100$ 
S-5. Fluorescent labelling of modified dextran with N-Methylisatoic anhydride (MIA)

Functionalization of PECA-Dex100G8 nanoparticles with MIA: confocal microscopy image of a PBS suspension of PECA-Dex100G8 nanoparticles tagged with MIA ((543 nm laser excitation; bandpass filter 350 - $445 \mathrm{~nm}$ ).

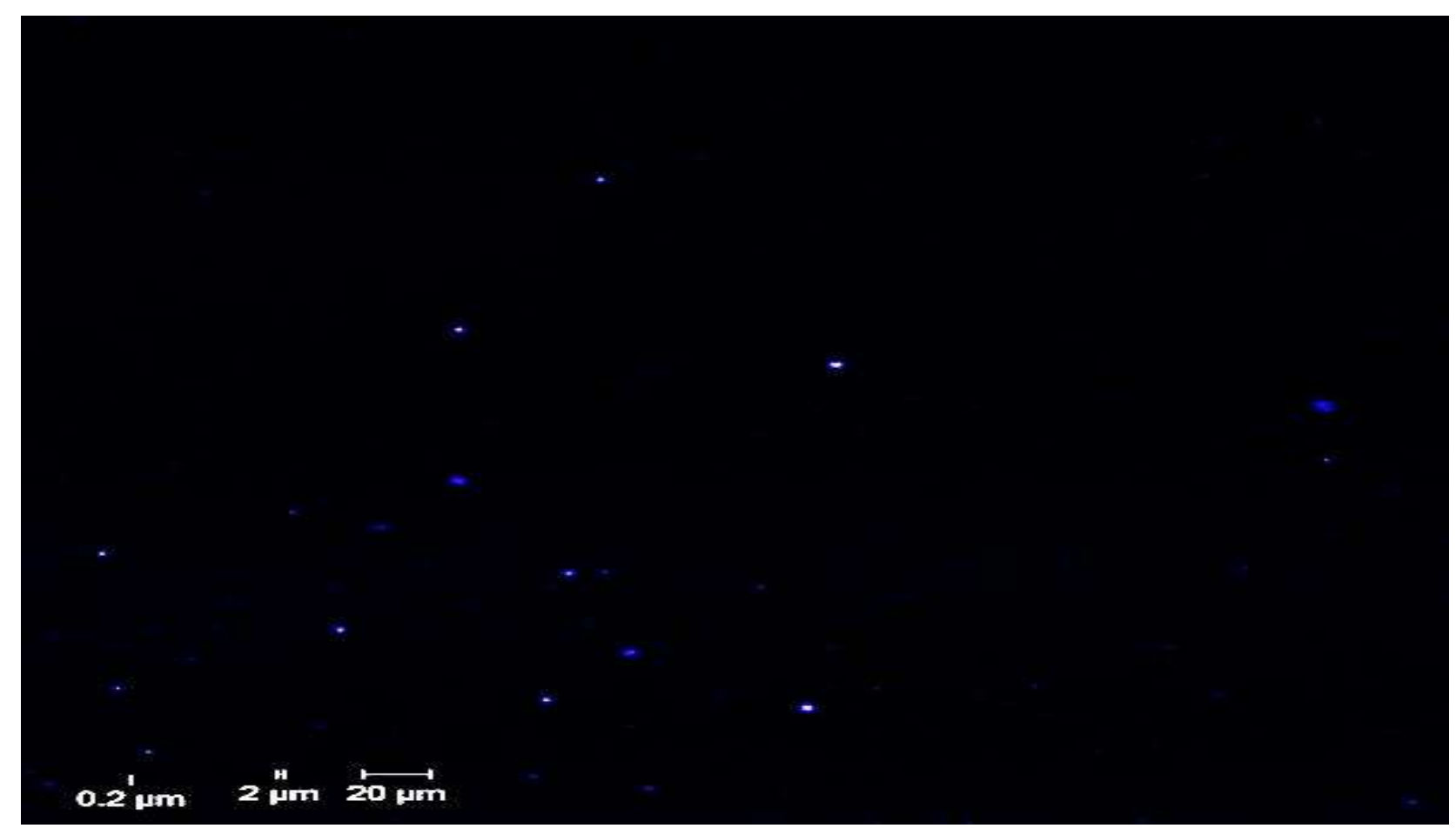

